\title{
Current Strategies to Improve Engraftment in Cord Blood Transplantation
}

\section{Robert Danby ${ }^{1-3 *}$ and Vanderson Rocha ${ }^{1-3}$}

${ }^{1}$ Department of Haematology, Oxford University Hospitals NHS Trust, Churchill Hospital, Oxford, UK

${ }^{2}$ NHS Blood and Transplant, Oxford Centre, John Radcliffe Hospital, Oxford, UK

${ }^{3}$ Eurocord, Hôpital Saint Louis APHP, University Paris VII IUH Paris, France

\begin{abstract}
Umbilical cord blood (UCB) remains an important alternative source of hematopoietic stem cells (HSC) for allogeneic transplantation when suitable HLA-matched donors are unavailable. Cord blood (CB) offers many benefits including rapid availability, absence of risk to the donor, and a low incidence of graft-versus-host disease. However, although the overall survival of patients receiving unrelated CB transplants is comparable to using other HSC sources, UCB transplantation is associated with delayed engraftment and poor immune reconstitution, particularly in adults. While this is partly due to the lower cell dose in UCB grafts, it may also reflect the relative immaturity of cord blood. Therefore, many different strategies to enhance hematopoietic engraftment following UCB transplantation are currently under investigation. This article will review the latest techniques including improved collection, HLAmatching, homing and expansion of $\mathrm{CB}$, and the use of double CB grafts, third-party donors, and accessory cells. As many of these methods are now in clinical trials, it is anticipated that UCB transplantation will continue to improve, further expanding our understanding of CB biology and HSC transplantation.
\end{abstract}

Keywords: Umbilical cord blood; Hematopoietic stem cell transplantation; Engraftment; Neutrophil recovery; Platelet recovery

\section{Introduction}

Allogeneic hematopoietic stem cell (HSC) transplantation is a potential curative therapy for many hematological conditions, particularly malignant disorders such as leukemia and lymphoma. Following conditioning with chemotherapy and/or radiotherapy, the transfer of HSC from a healthy donor into the immunosuppressed recipient generates new hematopoiesis, rescuing the host from severe prolonged aplasia. Long-term cure can then be achieved through the development of an immune mediated graft-versus-tumor (GvT) response, formed by the new donor-derived immune system.

HSC for allogeneic transplantation are usually obtained from a healthy sibling or unrelated donor, matched for the major class I (A, B, and C) and class II (DRB1, DRQ1) human leukocyte antigens (HLA) (10/10 match). The availability and choice of donor is primarily determined by the size of the family and the HLA-type of the recipient. Since any full sibling has only a one-in-four chance of being HLA-matched at all loci, only around $30 \%$ of all potential transplant recipients have a suitable HLA-matched sibling donor $[1,2]$. For the remainder, an HLA-allele matched unrelated donor may be found through national and international volunteer unrelated donor registries, including over 23 million donors currently on the Bone Marrow Donors Worldwide (BMDW) database [3]. However, certain ethnic groups or HLA-types are relatively under-represented in these registries and some populations have a greater diversity of HLA-types [2]. Therefore, if unrelated HSC donors cannot be found, alternative donor sources can be considered, including umbilical cord blood (UCB), HLA-mismatched unrelated donors or haploidentical family members.

UCB is an established alternative source of HSC for allogeneic transplantation with over $30000 \mathrm{UCB}$ transplants having been performed worldwide $[1,4]$. Due to the relative immaturity of cord blood (CB), the lower immunogenicity of UCB grafts, and the lower incidence of graft-versus-host disease (GvHD) compared to bone marrow (BM) and peripheral blood stem cell (PBSC) transplants, less stringent HLA-matching has traditionally been required [5-7]. Until recently, only HLA matching at HLA-A and HLA-B (serological) and HLA-DRB1 (allelic) were commonly used, with mismatches at one or two loci usually tolerated if sufficient cell doses were transplanted [8]. With over 600000 frozen UCB units stored in cord blood banks worldwide, unrelated UCB transplantation is now an option for many patients that lack a suitable HLA-matched sibling or unrelated donor [1]. UCB also has the advantage of being immediately available, avoiding further delays to transplantation, and without any associated risks to the donor [1].

While UCB has increased the applicability of HSC transplantation, UCB transplantation has previously been associated with high rates of graft failure, delayed engraftment, poor immune reconstitution, and increased risk of opportunistic infection [6,7,9-11]. This is partly due to lower cell dose since each $\mathrm{CB}$ unit (CBU) contains a one to two log lower total cell dose compared to BM and PBSC harvests (PBSCH) [12]. However, the biological properties of $\mathrm{CB}$ and the relative immaturity of $\mathrm{CB}$ cells may also be a factor. $\mathrm{UCB} \mathrm{CD} 34^{+}$cells have a more immature phenotype and CB immune cells (T-, B-, natural killer $(\mathrm{NK})$, and dendritic cells) are antigen inexperienced (naïve), being less responsive to allogeneic stimulation and producing lower levels of effector cytokines [13-15].

Within this article, the main factors influencing hematopoietic recovery following UCB transplantation will be discussed. This review will summarize the latest results of current strategies being used to improve engraftment, including improved collection, HLA-matching,

*Corresponding author: Robert Danby, Department of Haematology, Oxford University Hospitals NHS Trust, Churchill Hospital, Old Road, Headington, Oxford, OX3 7LE, UK, Tel:+44 1865572367; Fax: +44 1865 235288; E-mail: robert.danby@ouh.nhs.uk

Received January 23, 2014; Accepted February 12, 2014; Published February 14,2014

Citation: Danby R, Rocha V (2014) Current Strategies to Improve Engraftment in Cord Blood Transplantation. J Stem Cell Res Ther 4: 172. doi:10.4172/2157 7633.1000172

Copyright: (C) 2014 Danby R, et al. This is an open-access article distributed under the terms of the Creative Commons Attribution License, which permits unrestricted use, distribution, and reproduction in any medium, provided the original author and source are credited. 
homing and expansion of $\mathrm{CB}$, and the use of double $\mathrm{CB}$ grafts, thirdparty donors, and accessory cells (Table 1).

\section{Biology of HSC Engraftment}

Following conditioning therapy (chemotherapy and/or Total Body Irradiation (TBI)), the UCB graft(s) is intravenously infused into the recipient. The $\mathrm{CB}$ cells pass through the recipient's circulation to the $\mathrm{BM}$ microvasculature, where a highly regulated process of adhesion and migration allow homing of HSC and early hematopoietic progenitor cells (HPC) into the BM niche. In mouse models, only around $10 \%$ of intravenously infused HSC actually reach the BM, the rest being sequestrated in the lungs, liver and spleen $[16,17]$. Within the BM sinusoids, cell adhesion molecules (CAM), particularly P-and E-selectin, allow adhesion and rolling of the HSC along the endothelial walls [18]. Additional cell-to-cell interactions, using the integrins CD49d/CD29, $\mathrm{CD} 49 \mathrm{e} / \mathrm{CD} 29$, and CD11a/CD18, are then required for firm adhesion of the HSC to the endothelium and migration across the endothelial layer and basal membrane into the BM microenvironment $[18,19]$. Transient inhibition of vascular endothelial cadherin (VE-cadherin, $\mathrm{CD} 144$ ) by $\mathrm{CD} 34^{+} \mathrm{HSC}$ may also enhance migration by impairing tight adherens junctions between endothelial cells, increasing sinusoidal permeability [20]. The HSC migrate to the paratrabecular niche where they engraft, proliferate, and differentiate into full hematopoiesis. Over time, the number of HSC in the paratrabecular regions gradually falls as the corresponding number of cells in the highly vascular central region expands [21].

Homing, migration and engraftment of HSC to the BM are highly dependent upon chemotactic signals. Stromal Cell-Derived Factor-1 (SDF-1) (chemokine (C-X-C motif) ligand 12 (CXCL12)) is arguably the most important chemo-attractant for HSC engraftment, although

\section{Increasing cord blood cell dose}

- Improved CB collection, processing, freezing, and thawing.

Consecutive infusion of two CBUs (RS; Prospective phase II/III clinical trials; Clinical use).

\section{- Ex vivo expansion of $\mathrm{CB}$ (Phase $\mathrm{I} / \mathrm{II} / \mathrm{III}$ clinical trials).}

Infusion of CBU with third-party donor cells (Phase II clinical trials).

2. Improved delivery and homing HSC to bone marrow niche

Direct intra-bone infusion of CB (Phase $1 /$ II clinical trials).

Inhibition of CD26 peptidase (Phase II clinical trials).

Ex vivo Fucosylation of CB HSC/HPC (Phase I/II clinical trials).

3. Improved selection of $\mathrm{CBU}$

-Enhanced HLA-matching (RS; PSO).

-Detection of donor specific HLA-antibodies (RS; PSO).

Use of KIR matching (RS).

\section{Modification of transplant protocol}

- Using reduced intensity conditioning (RS; Prospective phase II/II clinical trials; Clinical use).

- Modification of graft-versus-host disease prophylaxis (RS; PSO).

\section{Post-transplant use of growth factors/cytokines}

- Administration of granulocyte colony stimulating factor (GCSF) (Regular clinical use).

- Administration of stem cell factor (SCF) (Pre-clinical studies).

Administration of Eltrombopag (Phase II clinical trials).

6. Infusion of $\mathrm{CB}$ with accessory cells

- Use of Mesenchymal stem cells (Phase I/II clinical trials).

- Use of regulatory T cells (Phase I/II clinical trials).

Table 1: Current strategies to improve engraftment following umbilical cord blood transplantation. (CB: Cord Blood; CBU: Cord Blood Unit; HSC: Hematopoietic Stem Cells; HPC: Hematopoietic Progenitor Cells; HLA: Human Leukocyte Antigen; KIR killer Immunoglobulin-like Receptor; RS: Retrospective Studies; PSO: Prospective Observational Studies). other proteins, such as CXCL10 (IP-10), CCL2 (MCP-1), and SCF may also have a role [22-24]. SDF-1 levels, produced by BM stroma (endothelium and endosteum), are increased following conditioning therapy and the infused HSC follow the SDF-1 gradient towards the BM [25]. SDF-1 binds to its receptor, CXCR4 (fusin/CD184), on the surface of HSC, activating a series of second messenger pathways including guanine triphosphatases (GTPase) and phosphatidylinositol-3-kinase (PI3K) $[18,24]$. These signals increase expression of the integrins CD49/CD29 and CD11a/CD18 and induce cytoskeletal changes required for adhesion and migration of HSC across the endothelium [26]. Several factors also increase the sensitivity of CXCR4 on HSC to SDF-1, including complement (C3a), hyaluronic acid, VCAM-1, fibrinogen, and thrombin. Once engrafted, SDF-1 may also promote HSC proliferation and survival $[27,28]$.

In comparison to $\mathrm{BM}$ and PBSC harvests, there are important biological differences in $\mathrm{CB}$ that may influence hematopoietic recovery. CB contains a higher proportion of HSC and granulocytemacrophage progenitor cells within the $\mathrm{CD} 34^{+}$fraction [29]. However, $\mathrm{CB} \mathrm{CD} 34^{+}$cells have a less mature phenotype with a higher frequency of primitive $\mathrm{CD}^{2} 4^{+} \mathrm{CD} 38^{-}$multipotent progenitors but lower proportions of committed progenitors [30,31]. CB CD34 $4^{+}$cells have a greater proliferative and repopulating capacity in both in vitro and in vivo studies [32-35]. Gene expression profiling and transcriptional analysis of $\mathrm{CD}_{3} 4^{+}$cells from UCB and BM also shows differential expression of genes involved in adhesion, proliferation, differentiation, apoptosis, and engraftment [36-38]. There are also differences in the number, composition, and maturity of other cell populations within $\mathrm{CB}$, including T-cells, NK-cells, regulatory T-cells, and dendritic cells [13-15,39]. Therefore, delayed hematopoietic recovery after UCB transplantation may be due to the immaturity of CB HSC, needing more cell divisions before differentiating to marrow progenitors, or due to the lack of other cell populations that facilitate engraftment [6].

\section{Engraftment following UCB Transplantation}

Following infusion of the $\mathrm{CB}$ graft, there is an initial period of aplasia during which time the HSC engraft, proliferate, and differentiate. In UCB transplantation (UCBT), the time to neutrophil recovery (first of three consecutive days with a neutrophil count $>0.5$ $\left.\times 10^{\%} / 1\right)$ is longer than with other sources of HSC, with a median time of approximately 26-30 days for UCB, 21 days for BM, and 14 days for PBSCH $[5-8,40,41]$. Platelet recovery is also longer with a median time to engraftment (first of three consecutive days with an unsupported platelet count $>20 \times 10^{9} / \mathrm{l}$ ) in UCBT ranging from 50 100 days. Graft failure is also higher following UCBT at around 10\% to $30 \%[4,6-10,41,42]$. As a consequence, UCBT has a significant risk of infection-related morbidity and mortality. In a retrospective analysis of infectious complications in 35 consecutive double UCBT for high-risk hematological disease, there were 99 infectious events, 77 of which occurred within the first 100 days post-transplant [41]. There were 34 confirmed severe bacterial infections in 19 patients with a 30-day cumulative incidence of first infection of $43 \%(95 \%$ Confidence Intervals (CI), 35-51\%). 21 of these infections were grampositive bacteria and the remainder gram-negative bacilli. The 100 day cumulative incidence of first bacterial infection was 55\% (95\% CI, 47-63\%). In addition, there were 14 fungal infections in 12 patients with a 30-day cumulative incidence of $12 \%$ (95\% CI, 10-14\%). Nine were invasive aspergillosis and three were candida septicemia. The Eurocord group also retrospectively analyzed infections in 510 UCBTs performed between 1994 and 2001 (unpublished study, V Rocha personal communication). $75 \%$ recipients were children and $78 \%$ had 
Citation: Danby R, Rocha V (2014) Current Strategies to Improve Engraftment in Cord Blood Transplantation. J Stem Cell Res Ther 4: 172. doi:10.4172/2157-7633.1000172

malignant disorders. All received single $\mathrm{CBU}$ using myeloablative conditioning and $85 \%$ received Anti-Thymocyte Globulin (ATG). The cumulative incidence of neutrophil recovery was $75 \%$ and non-relapse mortality (NRM) by day 100 was $32 \%$. There were 686 episodes of severe infection in 352 patients within the first 100 days post-UCBT. Of these, 404 were bacterial (gram-positive 277, gram-negative 122, others five) in 248 patients; 189 were viral (142 cytomegalovirus, 21 adenovirus, 12 Epstein-Barr virus, seven human herpes virus-6, seven others) in 164 patients; 54 were fungal (26 candida, 20 aspergillosis, eight others) in 53 patients; five were toxoplasmosis in five patients; 34 were of unknown origin in 31 patients. The cumulative incidence of first severe infection by day 100 was $69 \%$ ( $49 \%$ for bacterial, $32 \%$ for viral, $10 \%$ for fungal and $1 \%$ for toxoplasmosis). In multivariate analysis, long time to engraftment was independently associated with the incidence of overall infection (Hazard Ratio (HR) 3.34, $P<0.001$ ), bacterial infection (HR 4.54, $P<0.001$ ), viral infection (HR2.50, $P<0.001$ ), and fungal infection (HR 5.88, $P=0.02$ ). Shortening the time to engraftment may therefore decrease the incidence of infections after UCBT, possibly reducing morbidity and mortality.

Infection is a major contributing cause in $25 \%$ to $45 \%$ of deaths post-UCBT, particularly within the first three months post-transplant [4,6,9,41]. In a Grupo Español de Trasplante Hematopoyético (GETH) study of 192 consecutive adult unrelated allogeneic hematopoietic stem cell transplants (HSCT), the 100-day and 3-year infection-related mortality (IRM) for UCBT $(n=48)$ was $30 \%(95 \%$ CI $10-40 \%)$ and $40 \%$ (95\% CI 12-58\%) respectively [43]. However, although infection remains a major concern, it is still unclear whether UCBT has a significantly higher proportion of deaths due to infection compared to other forms of HSCT. In an International Bone Marrow Transplant Registry (IBMTR) comparison of unrelated donor transplants for leukemia, Laughlin and colleagues reported the proportion of deaths due to infection within 100 days as $45 \%, 21 \%$, and $24 \%$ for UCB $(n=150)$, HLA-matched marrow $(n=367)$, and HLA-mismatched marrow $(n=83)$ respectively $(P=0.01)$ [10]. However, Rocha and colleagues (2004) observed that a similar proportion of transplant deaths were due to infection when comparing CB (42\%) to unrelated BM (41\%) [7]. In the Spanish GETH study, although UCBT had a higher risk of severe infection compared to BM/PBSC transplants ( $85 \%$ v $69 \%, P<0.01$ ), the 100 -day IRM ( $30 \%$ v $28 \%$ v $22 \% ; P=0.2)$ and 3 -year IRM ( $40 \%$ v $42 \%$ v $38 \%, P=0.5$ ) were not significantly different [43]. Likewise, in a study of serious infections in the two years post-transplant in 136 pediatric myeloablative conditioning (MAC) unrelated donor transplants, the cumulative incidence of one or more infections was not significantly different between BM (81\%), T-cell depleted BM (83\%), or UCB $(90 \%)(P=0.12)$. In multivariate analysis of all infections, there was no significant difference between BM and UCB (Relative Risk (RR) 1.0, $P=0.84$ ). The proportion of patients in which infection was a causal or contributing factor towards death was also not significantly different (BM 36\%, T-cell depleted BM 33\%, UCB 30\%) [44]. Therefore, although UCBT is associated with delayed engraftment compared to BM and PBSC transplants, it appears that a similar proportion of deaths are due to infection for all three HSC sources. This may be due to the higher rates of GvHD and subsequent immunosuppression and infections seen with BM and PBSC transplants. Improved strategies to reduce infection-related mortality for all forms of allogeneic HSCT are therefore required.

\section{Main Factors Influencing UCB Engraftment}

\section{Cell dose and HLA-matching}

Seminal publications in the late 1990s established that the probability of UCB engraftment and the time to neutrophil recovery were significantly associated with cell dose (Total Nucleated Cells (TNC) or CD34 ${ }^{+}$cells per recipient weight) and the degree of HLAmatching (HLA-A and -B (antigen), HLA-DRB1 (allelic)) [5,9]. Subsequent retrospective series further demonstrated the importance of cell dose and the interaction with the number of HLA-disparities. In a Eurocord study of 550 UCBT, the number of HLA-mismatches and the TNC dose at freezing were significantly associated with neutrophil recovery [45]. Furthermore, neutrophil engraftment showed a loglinear relationship with the number of HLA-disparities. The cumulative incidence of neutrophil recovery by day 60 ranged from $83 \%$ for HLAmatched UCBT to $53 \%$ for $3 / 6$ HLA-mismatched UCBT. In a CIBMTR review of 503 pediatric UCBT and $282 \mathrm{BM}$ transplants, the incidence of neutrophil and platelet engraftment was similar for BM and HLAmatched (6/6) UCB [46]. However, UCB matched at only $5 / 6$ or $4 / 6$ HLA-loci had lower probabilities of neutrophil and platelet recovery, although higher TNC doses $\left(>3 \times 10^{7} / \mathrm{kg}\right)$ for the 5/6 HLA-matched UCBT was associated with improved platelet recovery. In light of these findings, in 2009, Eurocord published recommendations for the selection of CBUs [8]. When a single unit ( $6 / 6$ or $5 / 6$ HLA-matched) contained insufficient cells (TNC $<2.5 \times 10^{7} / \mathrm{kg}$ upon freezing, $<2.0 \times$ $10^{7} / \mathrm{kg}$ on thawing), double UCBT was recommended, aiming for a combined TNC dose $>3.0 \times 10^{7} / \mathrm{kg}$. Higher doses were proposed if the $\mathrm{CBU}$ was only $4 / 6$ HLA-matched (TNC $>3.5 \times 10^{7} / \mathrm{kg}$ upon freezing, $>2.5 \times 10^{7} / \mathrm{kg}$ on thawing) and CBUs with three or more HLAmismatches were not routinely recommended.

In 2010, Barker and colleagues further characterized the interaction between cell dose and HLA-matching in a retrospective analysis of 1061 MAC single UCBT in patients with leukemia or myelodysplasia [47]. The cumulative incidence of neutrophil engraftment by day 77 was $74 \%(95 \% \mathrm{CI}, 71-77 \%)$ and platelet engraftment $\left(>50 \times 10^{9} / \mathrm{l}\right)$ $46 \%$ (95\% CI $43-49 \%$ ) by nine months post-transplant. TNC dose was associated with neutrophil and platelet engraftment is a doseresponsive manner. Using a TNC dose of $2.5-4.9 \times 10^{7} / \mathrm{kg}$ as the reference group, the HR for neutrophil engraftment were (i) TNC 0.7-2.4 × 107/ kg: 0.7 (95\% CI 0.6-0.8), $P<0.001$; (ii) TNC 5.0-9.9 $\times$ 107/ kg: 1.2 (95\% CI 1.0-1.5), $P<0.001$; (iii) TNC $>10.0 \times 10^{7} / \mathrm{kg}: 1.8$ (95\% CI 1.3-2.5), $P<0.001$. Comparable results were observed with platelet engraftment. Similarly, HLA-matching was also associated with neutrophil and platelet engraftment in a progressive manner, although no significant difference was observed in neutrophil recovery between UCBT with one and two HLA-mismatches. Using the 5/6 HLA-match as the reference group, the HR for neutrophil engraftment were (i) Matched (6/6): 1.8 (95\% CI 1.3-2.5), $P<0.001$; (ii) 4/6 HLAmatch: 1.0 (95\% CI 0.9-1.2), $P=0.90$; (iii) 3/6 HLA-match: 0.8 (95\% CI $0.6-1.1), P=0.16$. There were 130 deaths due to graft failure with TNC dose, center experience, and year of transplantation independently associated with these events. Analyzing the interaction between TNC dose and HLA-matching (reference group was CBU with 5/6 HLAmatch and TNC $2.5-5.0 \times 10^{7} / \mathrm{kg}$ ) on engraftment, transplant related mortality (TRM), and overall mortality demonstrated that the best outcome was for matched UCBT (6/6) irrespective of TNC. UCBT using CBU with a 5/6 HLA-match and TNC $>2.5 \times 10^{7} / \mathrm{kg}$ or $4 / 6$ HLAmatch and TNC>5.0 $\times 10^{7} / \mathrm{kg}$ were next. Of note, using CBUs with a $4 / 6$ HLA-match and TNC $>5.0 \times 10^{7} / \mathrm{kg}$ had faster engraftment than CBU with a 5/6 HLA-match and TNC dose $>2.5 \times 10^{7} / \mathrm{kg}$ although there was no significant difference in survival. Transplants using CBU with a $4 / 6$ HLA-match and TNC $2.5-5.0 \times 10^{7} / \mathrm{kg}$ had higher mortality, followed by CBU with a 4-5/6 HLA-match and TNC $<2.5 \times 10^{7} / \mathrm{kg}$ or a 3/6-HLA match. As a result of these findings, it was recommended that when selecting CBUs, priority should be given to HLA-matched units, 
Citation: Danby R, Rocha V (2014) Current Strategies to Improve Engraftment in Cord Blood Transplantation. J Stem Cell Res Ther 4: 172. doi:10.4172/2157-7633.1000172

followed by single HLA-mismatched units with TNC>2.5 $\times 10^{7} / \mathrm{kg}$ or two HLA-mismatches with TNC>5.0 $\times 10^{7} / \mathrm{kg}$.

While many of these studies retrospectively analyzed the outcomes of UCBT using CB typed for HLA-A and -B (antigen) and HLADRB1 (allelic), the importance of enhanced HLA-matching strategies had increasingly been recognized. Eapen and colleagues (2011) retrospectively analyzed the impact of HLA-typing at HLA-A, -B, and -C (intermediate resolution) and HLA-DRB1 (allelic) on 803 single UCBT for acute leukemia $(n=727)$ or myelodysplasia $(n=76)$ [48]. Neutrophil recovery at day 28 was significantly lower for transplants mismatched at three/four HLA-loci (matched 70\% (95\% CI 57-79\%); one mismatch 64\% (95\% CI 55-71\%); two 64\% (95\% CI 57-69\%); three 54\% (95\% CI 48-60\%); four $44 \%$ (95\% CI 32-55\%)). More specifically, mismatching at HLA-DRB1 in the presence of mismatches at any other two HLAloci and mismatching at HLA-A in the presence of mismatches at three or four HLA-loci were associated with inferior neutrophil engraftment. TRM was higher when CBU units were mismatched at two $(n=259$; HR 3.27 (95\% CI, 1.42-7.54), $P=0.006)$, three $(n=253$; HR 3.34 (95\% CI, 1.45-7.71), $P=0.005)$, or four loci ( $n=75$; HR 3.51 (95\% CI, 1.44-8.58), $P=0.006)$ compared to matched units $(n=69$; HR 1.00$)$. In addition, TRM using CBU mismatched at HLA-C was greater compared to fully matched CBU (8/8) (HR 3.97 (95\% CI, 1.27-12.40), $P=0.02)$. Additional matching at HLA-C was therefore recommended.

The impact of high resolution HLA-typing on engraftment has also been examined. In 2005, a retrospective analysis of high resolution typing at HLA-A, -B, -C, -DR, and -DQ from 122 UCB transplants, did not demonstrate any association between the number of HLAmismatches and neutrophil recovery. High-resolution mismatches at HLA-A in the direction of rejection were associated with reduced engraftment by day $60(87 \%$ v $65 \%, P=0.04)$. However, overall, there appeared to be little benefit from the additional high resolution typing [49]. Delaney et al. [50] reviewed high resolution typing (HLA-A, $-B,-C,-D R,-D Q$ ) in 53 reduced intensity conditioned (RIC) double UCBT. Neutrophil and platelet recovery were significantly faster in those UCBT with allelic matching at HLA-B, although there was no effect seen with HLA-A, -C, and -DQ. However, this study was not sufficiently powered to allow a direct comparison between using the standard or high-resolution HLA-matching strategies. Recently, in a joint CIBMTR and Eurocord analysis, Eapen et al. [51], analyzed the effect of high resolution typing on the outcomes of 1658 MAC single UCBT for hematological malignancy. Neutrophil recovery by day 28 was significantly lower for transplants mismatched (MM) at three or more alleles compared to fully matched CBU (Odds Ratio (OR) 0.56 (95\% CI 0.36-0.88) $P=0.01$; OR 0.55 (95\% CI 0.34-0.88) $P=0.01$; OR 0.45 (95\% CI 0.25-0.82), $P=0.009$ for three, four, and five MM respectively). UCBT performed with mismatches at three or more alleles also had inferior neutrophil recovery compared to transplants mismatched at one or two alleles only (3/4 MM OR 0.69 (95\% CI, 0.55-0.86), $P=0.001$; 5 MM OR 0.56 (95\% CI, 0.35-0.89), $P=0.01$ ). However there were no significant differences in recovery observed when considering mismatching at specific HLA loci. In this series, non-relapse mortality was also significantly associated with the degree of HLA-mismatch with the lowest risk observed in those transplants matched at the allelic level at HLA-A, -B, -C, and -DRB1. Single HLA-mismatches at HLA-A, -C, or -DRB1 were associated with increased NRM (HR 3.05 (95\% CI, 1.52-6.14), $P=0.02$; HR 3.04 (95\% CI, 1.28-7.20), $P=0.01$; HR 2.93 (95\% CI, 1.38-6.25), $P=0.005$ respectively). Importantly, using $\mathrm{CBU}$ with $\mathrm{TNC}<3.0 \times 10^{7} / \mathrm{kg}$ was associated with significantly higher NRM, independent of HLA-matching. However, compared to CBU containing TNC>3.0 $\times 10^{7} / \mathrm{kg}$, further increases in cell dose was not associated with a significantly lower NRM. Taken altogether, Eapen et al. [51] therefore proposed that single UCBT must have a minimum pre-cryopreserved TNC of $3.0 \times 10^{7} / \mathrm{kg}$. The best HLA-allele matched $\mathrm{CBU}$ should then be selected, although mismatches at one or two alleles are acceptable. However, $\mathrm{CBU}$ with mismatches at three or more alleles should only be used with caution due to the higher rates of graft failure and NRM.

For non-malignant conditions, the interaction between cell dose and HLA-matching remains less clear due to the different biology in these disorders, the effects of previous treatment, and the relative paucity of data compared to studies on hematological malignancies. Patients with chemotherapy naïve conditions, e.g. hemoglobinopathies, have a more functional immune system prior to transplantation, while heavily pre-transfused recipients are more likely to have HLAantibodies. In a Eurocord analysis of 270 single UCBT for nonmalignant conditions (BM failure $40 \%$, primary immunodeficiency $36 \%$, metabolic disorder 24\%), neutrophil and platelet engraftment were associated with cell dose [8]. HLA-matching was also important with a significant difference in engraftment between $\mathrm{CBU}$ matched at $5-6 / 6$ HLA loci compared to $\leq 4 / 6$ loci $(P=0.046)$. Increasing cell dose, except when $\mathrm{CBU}$ were mismatched at three or more loci, reduced the impact of HLA-mismatch. Therefore in 2009, Eurocord recommended that for non-malignant conditions, $\mathrm{CBU}$ s with higher cell doses should be selected [8]. In particular, for CBU matched at only 4/6 HLAloci, the recommended minimum cell dose was $4.0-5.0 \times 10^{7} / \mathrm{kg}$ at collection and $3.5 \times 10^{7} / \mathrm{kg}$ at infusion. CBUs with three or more HLAmismatches were not recommended. Further studies in UCBT for non-malignant conditions are required, particularly given the recent findings regarding the impact of cell dose and high-resolution typing in malignant disorders.

CBU cell dose and HLA-matching clearly have important implications for engraftment and mortality following UCBT. However, the minimum cell dose required and $\mathrm{CB}$ selection criteria remain under much debate, especially given that these recommendations are based upon retrospective analyses. Whether priority should be given to TNC dose or HLA-matching or whether increasing the minimum TNC dose from $2.5 \times 10^{7} / \mathrm{kg}$ to $3.0 \times 10^{7} / \mathrm{kg}$ improves UCBT outcomes will need to be determined in future studies. While improving outcomes, it is also important to ensure that $\mathrm{CB}$ selection criteria maintain the availability of UCBT to those patients that otherwise lack a suitable donor.

\section{Conditioning and GvHD prophylaxis}

The intensity and type of conditioning can influence the rate of engraftment following HSC transplantation [52]. HSC transplant conditioning has two roles; the first is myeloablation i.e. reducing the recipient's own hematopoiesis, decreasing residual tumor burden, and emptying the BM niche for the incoming graft. The second is immunosuppression i.e. reducing rejection, either of the graft by the host immunity (Host-versus-Graft (HvG)) or of the host by the incoming donor graft (Graft-versus-Host $(\mathrm{GvH})$ ). The extent to which any conditioning regimen contains these two components can be manipulated, depending on the recipient, the disease being treated, and the risk of rejection. Over the last decade, use of reduced intensity conditioning (RIC) regimens has increased in all forms of allogeneic HSCT, including pediatric and adult UCBT [53,54]. RIC regimens are less myeloablative but provide sufficient immunosuppression to allow donor engraftment. Disease eradication is then dependent upon the donor-derived T-cells recognizing residual tumor as 'non-self, producing an immune mediated Graft-versus-Tumor (GvT) response 
Citation: Danby R, Rocha V (2014) Current Strategies to Improve Engraftment in Cord Blood Transplantation. J Stem Cell Res Ther 4: 172. doi:10.4172/2157-7633.1000172

Page 5 of 15

[55]. Importantly, RIC regimens have lower toxicity, shorter periods of aplasia and reduced TRM, allowing HSCT to be performed in older patients and in those with significant co-morbidities.

In 2003, Barker and colleagues reported the results of 43 RIC UCBT using Fludarabine (200 mg/m2), TBI (200 cGy) and Busulphan $(8 \mathrm{mg} / \mathrm{kg})(\mathrm{Bu} / \mathrm{Flu} / \mathrm{TBI})$ or Cyclophosphamide $(50 \mathrm{mg} / \mathrm{kg})(\mathrm{Cy} / \mathrm{Flu} /$ TBI) $[56,57]$. The median cell dose was $3.7 \times 10^{7} / \mathrm{kg}$ and the UCB grafts $(93 \%)$ were 1-2 HLA antigen-mismatched. The cumulative incidence of sustained donor engraftment was 76\% (95\% CI, 56-96\%) for $\mathrm{Bu} / \mathrm{Flu} / \mathrm{TBI}$ recipients and $94 \%$ (95\% CI, 84-100\%) for Cy/Flu/ TBI recipients $(P<0.01)$. The median day of neutrophil recovery was 26 days (range, 12-30 days) and 9.5 days (range, 5-28 days) for the $\mathrm{Bu} / \mathrm{Flu} / \mathrm{TBI}$ and $\mathrm{Cy} / \mathrm{Flu} / \mathrm{TBI}$ recipients respectively. The cumulative incidence of platelet engraftment $\left(>20 \times 10^{9} / \mathrm{l}\right)$ by day 180 was $24 \%$ (95\% CI, 6-42\%) for Bu/Flu/TBI recipients and 80\% (95\% CI, 57-100\%) for $\mathrm{Cy} / \mathrm{Flu} / \mathrm{TBI}$ recipients $(P<0.01)$. Using this approach, Brunstein et al. [58] published a larger series of 110 UCBT using the Flu/Cy/TBI RIC regimen and ciclosporin/ mycophenolate mofetil (MMF) GvHD prophylaxis. Neutrophil recovery by day 42 was $92 \%$ with a median time of 12 days (range, $0-32$ days). Platelet recovery $\left(>50 \times 10^{9} / \mathrm{l}\right)$ by day 180 was $65 \%$ (95\% CI 54-76\%) at a median of 49 days (range 0-134 days). Graft failure occurred in 15 patients (seven primary, eight secondary). TRM was $19 \%$ (95\% CI, 12-26\%) at day 180 and $26 \%(95 \%$ CI, $18-34 \%)$ at three years. Overall survival at three years was $45 \%$ (95\% CI, 34-56\%). Following these results, the $\mathrm{Cy} / \mathrm{Flu} / \mathrm{TBI}$ RIC regimen have been widely used in UCBT. Recently several retrospective series, has demonstrated that the use of RIC UCBT for hematological malignancy has comparable results to RIC transplants using conventional sources of HSC [57-60]. Therefore, UCB remains a suitable alternative source of HSC for patients requiring a RIC transplant without a suitable HLAmatched donor.

Despite the large number of series reporting the results of RIC in UBCT, there is still a paucity of data directly comparing engraftment rates between RIC and MAC UCBT. Although the reported probability of engraftment appears comparable between RIC and MAC UCBT, several early RIC regimens without TBI or ATG had unacceptably high rates of graft failure [61,62]. This was particularly prevalent with non-malignant conditions and in chemo-naïve patients suggesting there was inadequate host T-cell suppression for engraftment [63]. In 2009, Cutler and Ballen [63] summarized the results of published RIC UCBT studies, with the median time to neutrophil recovery ranging from 12-24 days. While shorter than the 26 and 27 days reported for the two largest retrospective series of MAC UCBT, comparing the results from different retrospective series is inherently problematic due to the potential effects of other confounding factors. However, it was hypothesized that the lower toxicity seen with RIC regimens might attenuate the production of SDF-1 outside the BM stroma during to conditioning therapy. Hence, there would be less retention of HSC in other organs leading to improved BM engraftment. More recently, in a retrospective analysis of 119 adult patients with acute myeloid leukemia receiving an UCBT (RIC $n=74$, MAC $n=45$ ), the cumulative incidence of neutrophil recovery by day 42 was higher with RIC (94\% v 82\%) with a median of 10 days (range 5-39) v 23 days (range 13-38) $(P<0.01)$ [64]. Platelet recovery at 6 months was similar between the groups $(68 \% \mathrm{v}$ $67 \%$ ) with a median time to recovery of 55 days (range $0-181$ days) $\mathrm{v}$ 77 days (range $42-177$ days) $(P=0.3)$. In contrast, in a non-randomized study of MAC and RIC in 88 consecutive pediatric UCBT recipients, there was no difference in the incidence of graft failure (4/49 MAC v 5/39 RIC) or median time to neutrophil or platelet engraftment (MAC: 24 days and 118 days; RIC: 29 days and 53 days, $P=$ NS). However, the two groups differed significantly in terms of underlying disease $(P<0.001)$, disease status $(P<0.001)$, performance status $(P=0.04)$, and previous history of autologous SCT $(P<0.001)$ [65].

The use of particular chemotherapeutic agents and/or GvHD prophylaxis can also affect engraftment. In a Eurocord analysis of 226 single UCBT using MAC regimens, the use of Fludarabine in the conditioning was associated with improved neutrophil and platelet recovery when receiving lower cell doses [66]. Similarly, the use of a Fludarabine containing regimen in UCBT for patients with Fanconi anemia was associated with improved neutrophil engraftment $(72 \%$ $\pm 6 \%$ v $42 \% \pm 8 \%, P=0.02$ ) [67]. In multivariate analysis, use of Fludarabine (HR 1.86 (95\% CI, 0.99-3.47), $P=0.05$ ) and a higher cell dose (HR 1.78 (95\% CI, 1.07-2.97), $P=0.03$ ) remained independently associated with improved neutrophil recovery. In relation to GvHD prophylaxis, the use of methotrexate post-HSCT is associated with delayed myeloid engraftment [68,69]. Similarly, in UCBT methotrexate containing regimens have been associated with delayed engraftment and increased the risk of graft failure in patients with hemoglobinopathies transplanted with a related CBU [70]. For this reason, methotrexate is not commonly used following UCBT although several Japanese groups have reported that short term low-dose methotrexate following UCBT does not appear to impair engraftment but reduces post-transplant immune reactions (HR 0.55 (95\% CI 0.31$0.98), P=0.04)$ and improves overall survival a six months (59\% (95\% CI $42-73 \%)$ v 16\% (95\% CI 6.6-70\%), $P=0.0001$ ) [71,72]. In Europe and the United States, GvHD prophylaxis for UCBT usually contains a calcineurin inhibitor (Ciclosporin or Tacrolimus) with MMF or steroids. However, intensive administration of mycophenolate (1000 $\mathrm{mg}$ t.d.s. compared to $17.5 \mathrm{mg} / \mathrm{kg}$ b.d.) post-UCBT has been associated with delayed neutrophil engraftment (median 22 days (range, 1441 days) v 17 days (range, $14-48$ days), $P=0.02$ ) [73]. Furthermore, a recent combined GETH and Gruppo Italiano Trapianto Midollo Osseo (GIMTO) study analyzed the results from 227 MAC single UCBT using Busulphan/Thiotepa/Fludarabine/ATG with ciclosporin and steroids (GETH 2005 protocol, $n=88$ ) or ciclosporin and mycophenolate mofetil (GITMO 2008 protocol, $n=145$ ) [74]. Of note, the GITMO 2008 protocol also had a slight reduction in the ATG dose $(2 \mathrm{mg} / \mathrm{kg} /$ day days -4 to -2 vs. days -5 to -2 ). The cumulative incidence of myeloid engraftment at day 60 was $94 \%$ (95\% CI, 88-99\%) and 88\% (95\% CI, $82-93 \%)$ respectively, with a median time to recovery of 19 and 23 days $(P<0.0001)$. There was no significant difference in platelet recovery by day 180 (81\% (95\% CI, 72-89\%) vs.73\% (95\% CI, 66-80\%), $P=0.60)$. As recognized by the authors, this was a non-randomized study using an historical group (GETH2005) with slight differences in minimum cell dose requirements and ATG dose. Nevertheless, these observations, suggest that mycophenolate may have an adverse effect on myeloid engraftment and continued review of GVHD prophylaxis is required to improve $\mathrm{CB}$ engraftment.

\section{Strategies to Improve Engraftment}

\section{Increasing cell dose}

Improved collection, processing and storage: $\mathrm{CBU}$ are collected through sterile puncture and drainage of the umbilical cord immediately after delivery. However, many HPC/HSC remain in the placental vessels, with potentially as many HPC remaining in the placenta as are collected using standard methods [75]. Collection from the placental vessels and/or placental perfusion can, therefore, increase cell yields. However, it remains to be determined whether these methods are practical for routine $\mathrm{CB}$ collection and without increasing contamination from maternal cells [75]. Validated and standardized operating procedures 
for processing $\mathrm{CB}$ and cryopreservation are necessary to maximize cell recovery and ensure reliability between different cord blood banks. Immediate processing and/or storage of $\mathrm{CB}$ at $4^{\circ} \mathrm{C}$ are associated with higher post-thaw recovery and greater viability than storage at room temperature [76]. Furthermore, in vivo engraftment in mouse models was significantly impaired with CB stored at room temperature for 72 hours prior to processing. Use of modern automated systems for red cell depletion and volume reduction have also improved $\mathrm{CB}$ processing, although there is still an associated cell loss (TNC recovery $78.8 \% \pm 7.3 \%$ for Sepax $(n=670) ; 76.8 \% \pm 7.5 \%$ for APX $(n=1000))$ [77]. Furthermore, cryopreservation, thawing, and washing CB also causes a further $20 \%$ cell loss [78]. Therefore minimizing CB processing and improving good manufacturing compliant methods to enhance cell recovery could increase the number of cells available for infusion.

Double cord blood transplantation: If a single CBU cannot provide the recommended cell dose for transplantation (TNC or $\mathrm{CD}^{+} 4^{+}$cells), two CBUs from different donors can be infused, one after the other. Double cord blood transplantation was first reported in 2001 by the Minneapolis group when attempting to increase the cell dose given to adults and larger children [79]. Both units contribute to early engraftment, although eventually, one unit predominates [53]. In an analysis of 23 double UCBT following MAC, hematopoiesis was observed from a single donor in $76 \%$ patients at day 21 and $100 \%$ patients by day 100 [80]. Likewise, in 81 patients with sustained chimerism after receiving a double UCBT using a non-myeloablative regimen, single donor chimerism was detectable in $57 \%, 81 \%$, and $100 \%$ patients at day 21,100 , and 365 respectively [53]. Double UCBT show high rates of engraftment ( $85 \%$ to $100 \%)$ with the median time to neutrophil engraftment ranging from 9 to 33 days depending on the conditioning regimen and/or the use of GCSF $[53,81,82]$. Interestingly though, a significant difference in the cumulative incidence and rate of engraftment has not been demonstrated between patients receiving one or two CBUs $[42,53,54,83]$. As the double UCBT patients tend to be heavier, this would suggest an initial booster effect from the nonengrafting unit [84]. However, the incidence of grade II-IV acute GVHD appears to be higher in patients receiving double UCBT $[42,85]$. Similarly, a lower relapse risk has also been reported in patients receiving two CBUs for acute leukemia, possibly through an enhanced graft-versus-leukemia response [83].

Ruggeri et al. [41] reported the outcomes of 35 double UCBT in recipients with high-risk hematological diseases. The cumulative incidence of neutrophil recovery at day 60 was $72 \% \pm 8 \%$ ( $86 \%$ for malignant disorders) with a median time of 25 days (range, 11-42 days). The median time to platelet recovery was 50 days (range 28-152 days) with a cumulative incidence at day 180 of $54 \% \pm 10 \%$. The incidence of acute GVHD was $47 \%$ with an estimated overall survival of $48 \%$ at two years. More recently, in long-term follow-up of the 135 double UCBT in patients with hematological malignancies reported to the SGGMTC registry, the cumulative incidence of neutrophil engraftment by day 60 was $91 \%$ and 3-year overall survival 41\% [86]. Ruggeri et al. [42] then reported a Eurocord and EBMT comparison of single and double UCBT using MAC in adults with acute leukemia. The cumulative incidence of neutrophil engraftment by day 60 was not significantly different between the single and double UCBT $(82 \% \pm 6 \%$ v $90 \% \pm 6 \%$ respectively, $P=\mathrm{NS}$ ). However, in multivariate analysis, TNC $>3.2 \times 10^{7} /$ $\mathrm{kg}$ was independently associated with higher neutrophil engraftment (HR 0.63 (95\% CI, 0.36-0.86), $P=0.01$ ). Double UCBT had higher rates of grade II-IV acute GvHD although there was no difference in relapse. Leukemia Free Survival (LFS) was $43 \% \pm 3 \%$ at two years' post-UCBT.
With appropriate conditioning and sufficient cell dose, the overall results between single and double UCBT appear similar.

Cord blood expansion: Ex vivo cord blood expansion increases the number of HSC for long-term engraftment as well as enhancing the number of committed progenitors to attenuate the initial period of aplasia. The expanded CBU can then be given alone or in combination with an unmanipulated unit. The expanded unit improves early hematopoietic recovery but it is the unmanipulated unit that usually provides long-term engraftment [87]. UCB expansion has been achieved using several methods. In liquid culture, isolated $\mathrm{CD} 34^{+}$or $\mathrm{CD} 133^{+}$HSC are expanded in the presence of selected cytokines and growth factors, including stem cell factor (SCF), Thrombopoietin (TPO), Granulocyte Colony Stimulating Factor (GCSF), and/or fmslike tyrosine kinase 3 ligand (FLT-3-L) [88,89]. The optimal milieu of cytokines and growth factors remains uncertain but several groups have shown improved expansion by the addition if IL-3 and/or IL-6 [90]. Shpall et al. [88] performed a feasibility study in which CD34 ${ }^{+}$ cells were isolated from a fraction (40-60\%) of the UCB unit and expanded in liquid culture with SCF, GCSF, TPO, and megakaryocyte growth and differentiation factor. The remainder of the unit was infused with the expanded cells following myeloablative conditioning. The median TNC dose infused was $0.99 \times 10^{7} / \mathrm{kg}$ and the median time to engraftment was 28 days (range, 15-49 days) for neutrophils and 106 days (range, 38-345 days) for platelets. Using a modification to this approach, a phase I/II trial was performed in which $\mathrm{CD}_{133^{+}}$cells were isolated from a portion of the $\mathrm{CBU}$ and expanded in liquid cultures with SCF, FLT-3-L, IL-6, TPO, and the copper chelator TEPA [91]. The median TNC fold expansion was 219 (range, 2-260). Both expanded and unexpanded cells were infused, achieving a median TNC of $1.8 \times 10^{7} /$ $\mathrm{kg}$. Nine of the ten patients engrafted with a median time to neutrophil and platelet engraftment of 30 days (range, 16-46 days) and 48 days (range, 35-105 days) respectively. Delaney et al. [92] later reported results from a phase I trial using an immobilized Notch ligand delta-1 in addition to SCF, FLT-3-L, TPO, IL-3, and IL-6. Ten patients with high-risk leukemia were treated with a myeloablative double UCBT in which one unit was expanded using this protocol. The average fold expansion was 562 (range, 146-1496) for TNC and 164 (range, 41-471) for $\mathrm{CD} 34^{+}$cells. Nine of the ten patients engrafted with a median time to neutrophil engraftment of 16 days (range, 7-34 days). However, in contrast to other studies, there was predominance for donor $\mathrm{CD}_{3}{ }^{+}$and $\mathrm{CD}_{14}{ }^{+}$cell engraftment from the expanded unit. The second expansion method uses co-culture with a supporting network of Mesenchymal stromal cells to provide a hematopoietic microenvironment that supports HSC proliferation [93]. De Lima et al. [87] reported the results of 31 patients receiving two UCB units, one of which was expanded ex vivo with mesenchymal stem cells (MSC). This ex vivo culture system expanded TNC and CD34 $4^{+}$cells by a median factor of 12.2 and 30.1 respectively and the median TNC dose infused was $8.34 \times 10^{7} / \mathrm{kg}$. Of the 24 patients that received ex vivo expanded cells, 23 achieved neutrophil engraftment, at a median time of 15 days (range, 9-42 days), and 18 had sustained platelet engraftment, at a median time of 42 days (range, 15-62 days). Both compared favorably to 80 CIBMTR historical controls that received unmanipulated double UCBT only (neutrophil engraftment 24 days (range, 12-52 days), $P<0.001$; platelet engraftment 49 days (range, 18-264 days), $P=0.03$ ). Although the expanded CBU improved early hematopoietic recovery, in all cases, the unmanipulated unit provided long-term engraftment. Finally, HSC expansion has also been achieved using a continuous perfusion culture system in which cells are supplied with fresh culture media and gaseous exchange $[94,95]$. In a phase I study, Jaroscak et al. [94] expanded a portion of an UCB unit using a continuous perfusion culture device and infused 
these expanded cells 12 days after the remainder of the original unit. The median fold increase in TNC was 2.4 (range, 1.0-8.5). 21 of the 26 patients attained neutrophil engraftment with a median time of 22 days (range, 13-40 days). The median time for platelet engraftment was 71 days (range, $39-139$ days; $n=16$ ).

Although $\mathrm{CB}$ expansion appears promising, it remains to be determined if these strategies will enhance engraftment and improve clinical outcomes following UCBT. Furthermore, it needs to be established whether the increase in committed progenitors is at the expanse of long term HSC. There are many ongoing prospective clinical trials of CB expansion that will hopefully answer these questions, as well as looking at the cost effectiveness and practicality of such approaches [96]. The MD Anderson Cancer Centre are currently performing a phase I/II study to evaluate the safety and feasibility of transplantation using UCB expanded with MSC in patients with hematological malignancies (ClinicalTrials.gov NCT00498316). Similarly, a multicenter, randomized study to evaluate double UCBT with one of the CBUs expanded using MPC (Mesoblast) is recruiting (ClinicalTrials. gov NCT01854567). The Fred Hutchinson Cancer Centre has a multicenter randomized study of MAC double UCBT with or without infusion of off-the-shelf ex vivo expanded cryopreserved $\mathrm{CB}$ progenitor cells in hematological malignancies (ClinicalTrials.gov NCT01690520). Several studies are also using NiCord' ex vivo expanded UCB. A safety and efficacy study of transplanting a single $\mathrm{NiCord}^{\circledR}$ expanded CBU in patients with hematological malignancies is recruiting, while a similar study in double UCBT (one expanded CBU) has recently closed (ClinicalTrials.gov NCT01816230; NCT01221857) (Table 2).

Combined use of umbilical cord blood with third party donor: Sebrango et al. [97] reported the results of 55 combined UCB/ haploidentical transplants for high risk myeloproliferative and lymphoproliferative disorders. Patients received MAC followed by CB (median TNC $2.39 \times 10^{7} / \mathrm{kg}$ (range, 1.14-4.30); median CD34 ${ }^{+}$ $0.11 \times 10^{6} / \mathrm{kg}$ (range, 0.04-0.37)) and positively selected CD34 ${ }^{+}$and $/$ or $\mathrm{CD} 133^{+}$cells (median $2.4 \times 10^{6} / \mathrm{kg}$ (range, 1.05-3.34)) from a thirdparty haploidentical donor. Using this approach, the haploidentical graft provides early engraftment but it is the CB that provides longterm engraftment. The maximum cumulative incidence of neutrophil and platelet engraftment was $96 \%$ and $78 \%$ with a median time

\begin{tabular}{|l|c|}
\hline Main focus of clinical study & Number \\
\hline Using CB for specific hematological disorders & 22 \\
\hline Conditioning regimen & 22 \\
\hline Use of cellular therapy (e.g. T-cells) post-CB transplantation & 9 \\
\hline Use of expanded CBU & 9 \\
\hline Combined use of CB and Haploidentical grafts & 7 \\
\hline Use of unlicensed CBUs & 5 \\
\hline Direct intra-bone infusion of CB & 4 \\
\hline Combined use of two CBU & 3 \\
\hline Co-infusion of CBU with accessory cells (MSC/Tregs) & 3 \\
\hline Use of growth factors (Eltrombopag) post-UCB transplant & 3 \\
\hline UCB vs. Haploidentical transplantation & 2 \\
\hline Improved homing of UCB HSC & 2 \\
\hline T-cell depletion of CBU & 2 \\
\hline Fucosylation of CB HSC & 1 \\
\hline Management of GvHD infection post-CB transplantation & 2 \\
\hline Total clinical trials & 96 \\
\hline
\end{tabular}

Table 2: Current clinical trials in cord blood transplantation. Summary of the current clinical trials in unrelated cord blood transplantation for hematological conditions that are currently recruiting as registered with ClinicalTrials.gov (12/01/2014). (CB: Cord Blood; CBU: Cord Blood Unit; MSC: Mesenchymal Stem Cells; Tregs: Regulatory T-cells; GvHD: Graft-versus-host Disease). to recovery of 10 and 32 days respectively. Full UCB chimerism was achieved in 50 patients $(91 \%$ (95\% CI, 84-99\%)) with a median time of 57 days (range, 11-186 days). Liu et al. [98] transplanted 45 patients using a RIC regimen (Fludarabine/Melphalan/ATG) with an unrelated UCB graft and $\mathrm{CD} 34^{+}$selected cells from a haploidentical family member. The cumulative incidence of neutrophil engraftment was $95 \%$ at day 50 with a median time to recovery of 11 days. The cumulative incidence of platelet engraftment was $83 \%$ at day 100 with a median time to recovery of 19 days. The median percentage of $\mathrm{PB}$ cells of UCB origin was $10 \%, 78 \%$, and $95 \%$ at day 30,100 , and 180 respectively. Conversely, the median percentage of $\mathrm{PB}$ cells from the haploidentical graft was $86 \%, 22 \%$, and $2 \%$ at the corresponding times. The cumulative incidence of acute and chronic GvHD was $25 \%$ and $5 \%$ respectively, with NRM at one year $38 \%$, relapse $30 \%$, and overall survival $55 \%$. Interestingly, in this study the CB dose had no impact on time to hematopoietic recovery. It was therefore hypothesized that $\mathrm{CB}$ selection should be focused upon improved HLA-matching, potentially improving long-term outcomes. Recently, Chen et al. [99] reported a prospective study of 50 patients with hematological malignancy given a MAC combined UCB/Haploidentical transplant. However, in contrast to the previous studies, the haploidentical grafts were T-replete, with all surviving patients achieving sustained haploidentical engraftment (three had mixed chimerism). 48 patients engrafted within 20 days with a median time to neutrophil recovery of 13 days (range, 11-20 days) and platelet recovery of 15 days (range, 11-180 days). Other clinical outcomes such as GvHD were reportedly better than historical controls. Taken together, these studies highlight the possible benefits of combining UCB and haploidentical grafts. However, which graft eventually provides long-term hematopoiesis appears to be dependent upon using T-cell depletion of the haploidentical graft. Further prospective studies will be needed to determine whether either of these approaches significantly improves engraftment and other transplantrelated outcomes compared to UCBT alone. Several groups have ongoing phase II/III studies comparing double UCBT with a combined haploidentical/UCB approach in hematological disease (ClinicalTrials. gov NCT01050964; NCT01745913; NCT00943800).

\section{Additional considerations for HLA-matching}

While an HLA-matched CBU, with sufficient cell dose, remains the ideal choice, this is not always feasible. Therefore, consideration of other factors such as the direction of the HLA-mismatch and the detection of HLA-antibodies may be important. If a recipient is homozygous at an HLA-locus but the donor heterozygous at the same site (one antigen/ allele matching the recipient), there is a mismatch is in the host-versusgraft (HvG) direction (i.e. risk of rejection). Conversely, if the donor is homozygous but the recipient heterozygous at the same HLA-locus (one antigen/allele matching the donor), the mismatch is in the graftversus-host $(\mathrm{GvH})$ direction. When a mismatched antigen/allele is present in the recipient and donor, the mismatch is bidirectional. In 2011, Stevens and colleagues analyzed the implications of HLAmismatch direction in 1202 single UCBT [100]. 890 transplants had bidirectional HLA-mismatches, $58 \mathrm{GvH}$-mismatches only, $40 \mathrm{HvG}$ mismatches only and 145 had other combinations. Recipients of HvGmismatches only had a trend towards lower myeloid engraftment compared to those with a single bidirectional mismatch (HR 0.7 (95\% CI, 0.4-1.1), $P=0.1$ ). Conversely, those with no HLA-mismatches or GvH-mismatches only had improved engraftment (HR 1.5 (95\% CI, 1.1-2.0), $P=0.006$; HR 1.6 (95\% CI, 1.2-2.2), $P=0.003$ respectively). In subgroup analysis of those with hematological malignancies, recipients of CBU with HLA-mismatches in the $\mathrm{GvH}$ direction only also had lower treatment failure (HR 0.5 (95\% CI, 0.3-0.9), $P=0.02$ ) and lower overall 
mortality (HR 0.5 (95\% CI, 0.3-0.9), $P=0.02$ ). In a similar Japanese study of 2977 single UCBT, recipients of CBU with HLA-mismatches in the $\mathrm{GvH}$ direction only showed a trend towards improved neutrophil and platelet recovery compared to single bidirectional mismatched transplants (HR 1.18 (95\% CI 0.98-1.42); P=0.08; HR 1.23 (95\% CI $1.00-1.51$ ); $P=0.05$ respectively) [101]. However, in a recent Eurocord analysis of 1565 single UCBT, neutrophil and platelet recovery showed no significant difference between these corresponding groups [102]. Furthermore, in these later two studies, HLA-mismatches (one or two) in either direction were not associated with significant differences in overall mortality or survival. Therefore, although possibly influencing engraftment, the recently published data does not show that the direction of HLA-mismatch has a significant impact on overall survival after UCBT. As such, selection of CBU based upon the direction of HLA-mismatch is not routinely recommended.

In contrast, the detection of anti-HLA donor specific antibodies (DSA) should be considered. In a retrospective analysis of 386 MAC single UCBT for hematological malignancy, 89 patients had antiHLA antibodies, of which 20 had specificity against the CBU [103]. In multivariate analysis, neutrophil and platelet recovery were significantly worse in these 20 patients compared to the antibody negative group (RR 0.23 (95\% CI, 0.09-0.56), $P=0.001$; RR 0.31 (95\% CI, 0.12-0.81), $P=0.02$ respectively). Similar findings were demonstrated in 73 double UCBT where the presence of DSA was associated with increased graft failure $(5.5 \%$ v $18.2 \%$ v $57.1 \%$ for none, single, or dual DSA positivity; $P=0.0001$ ) and longer neutrophil recovery (median 29 days (any DSA) v 21 days (no DSA), $P=0.04$ ). The presence of DSA was also associated with inferior three-year survival $(0.0 \% \mathrm{v} 45.0 \%, P=0.04)$ [104]. More recently, a retrospective Eurocord analysis on the impact of DSA in 294 RIC UCBT was performed. $21 \%$ recipients had anti-HLA antibodies of which $14(5 \%)$ had donor specificity. Day 60 neutrophil engraftment ( $44 \%$ v $81 \%, P=0.006)$ and one year TRM ( $46 \%$ v $32 \%, P=0.06)$ were inferior in the presence of DSA. In light of these observations, it is recommended that recipients should be screened for anti-HLA antibodies before transplant and only CBUs selected that do not have the specificity of the anti-HLA antibodies.

The implication of NK-cell alloreactivity for CB engraftment remains less clear. NK-cell alloreactivity derives from a mismatch between the inhibitory receptors for self-MHC class I molecules on NK cells (killer cell Immunoglobulin like Receptors (KIR)) and MHC class I antigens on recipient cells [105]. In haploidentical HSC transplantation, KIRligand incompatibility in the $\mathrm{GvH}$ direction has been associated with reduced graft failure, GvHD, relapse, and improved survival [105-107]. In a Eurocord analysis of 218 single UCBT for acute leukemia, KIR ligand incompatibility in the $\mathrm{GvH}$ direction was not associated with the cumulative incidence of neutrophil recovery [108]. However, it was independently associated with reduced relapse (HR 0.53 (95\% CI, 0.30.99), $P=0.05$ ) and improved overall survival (HR 2.0 (95\% CI, 1.2-3.2), $P=0.004)$. In contrast, the Minnesota group showed no effect of KIR mismatch on TRM, relapse, or survival in MAC UCB transplants [109]. Furthermore, in the RIC UCBT subset, KIR mismatch was associated with worse GvHD, TRM, and survival. The impact on engraftment was not specifically analyzed. In a more recent analysis of 80 double UCBTs, engraftment did not differ between groups receiving transplants from KIR ligand-compatible or incompatible donors. The median time to recovery of neutrophils and platelets was 21 days $(P=0.3)$ and 42 days $(P=0.95)$ in both groups respectively [110]. There was no significant effect on relapse, PFS, or OS. In keeping with these findings, Tanaka and colleagues (2013) found no association between KIR ligandincompatibility in the GVH direction and the incidence of GvHD, relapse, NRM, and overall survival in single UCBT without ATG [111]. However, in multivariate analysis, engraftment was significantly lower in the acute lymphoblastic leukemia subset when a KIR incompatibility was present in the HvG direction (HR 0.66 (95\% CI, 0.47-0.91), $P=0.01)$. Overall, the available data does not currently support the routine use of KIR matching in the selection of CBU. However, further studies are warranted particularly for assessing the impact of HvG KIR incompatibility on engraftment.

\section{Improving delivery and homing of HSC}

To overcome the potential hurdles with homing of HSC to the $\mathrm{BM}$ niche and/or sequestration within other organs, direct intrabone infusion of $\mathrm{CB}$ has been proposed. In animal models, intrabone injection of $\mathrm{BM}$ and $\mathrm{CB}$ was associated with greater seeding efficiency, long-term maintenance of donor hematopoiesis and significantly higher longterm survival $[112,113]$. In a phase I/II study, 32 consecutive patients with acute leukemia received an UCBT using intrabone infusion [114]. No complications occurred during administration. The median time to neutrophil and platelet recovery was 23 days (range, 14 -44 days; $n=28$ ) and 36 days (range, $16-64$ days; $n=27$ ) respectively and all engrafted patients showed full donor chimerism from day 60. 16 patients were alive and in remission with a median follow-up of 13 months. Okada et al. [115] demonstrated in a phase I study that intrabone infusion of unwashed cord blood following a RIC regimen was also well tolerated. In 10 patients, there were no injection related complications and the median time to neutrophil recovery was 17 days. Saglio et al. [116] also showed that intrabone injection was also well tolerated in children. In a recent Eurocord retrospective analysis of single unit intrabone UCBT ( $n=87)$ with double unit intravenous UCBT $(n=149)$, intrabone infusion was associated with improved neutrophil engraftment by day $30(76 \%$ v $62 \%, P=0.01)$ and improved platelet engraftment by day $180(74 \%$ v $64 \%, P=0.003)$. In multivariate analysis adjusting for differences between the groups, intrabone UCBT had improved neutrophil recovery by day 30 (HR 1.5 (95\% CI, 1.04-2.17, $P=0.03$ ) and greater platelet recovery by day 180 (HR 1.97 (95\% CI, 1.35-2.29, $P=0.004)$ compared to intravenous UCBT. Intrabone infusion was also associated with a lower incidence of acute GvHD and showed a trend towards improved disease-free survival (DFS) [117]. Although not a prospective randomized trial, these results are clearly still encouraging. Further phase II non-randomized clinical trials are ongoing to evaluate engraftment kinetics and immune reconstitution following intrabone infusion of cord blood cells in hematological malignancies (ClinicalTrials.gov NCT00886522; NCT01332006; NCT01613066; NCT01711788).

Ex vivo priming of UCB with agents that promote migration and homing of HSC to the BM microenvironment may also enhance engraftment $[118,119]$. In mouse models, inhibition of the membrane bound extracellular peptidase dipeptidyl peptidase-4 (DPP4) (CD26), which cleaves SDF-1, enhances long-term engraftment in UCB $\mathrm{CD} 4^{+}$cells in NOD/SCID/beta 2 microglobulin null mice [120,121]. Alternatively, fucosylation (the addition of a fucose) of ligands expressed on HSC may enhance engraftment. Fucosylation of UCB HSC (CD34 $4^{+} \mathrm{CD} 38^{-/ \text {low }}$ cells) is required for interaction with $\mathrm{P}$ - and E-selectin expressed in the BM microvasculature. Treatment of UCB HSC with Guanosine Diphosphate (GDP) fucose and exogenous alpha 1-3 fucosyl transferase VI improved adhesion and rolling of the cells on P- and E-selectin under flow conditions. It also improved human HSC engraftment in irradiated NOD/SCID mice $[18,122]$. In NOD-SCID interleukin-2R $\gamma$ (null) mice, Robinson et al. [123] also demonstrated that only fucosylated UCB $\mathrm{CD} 34^{+}$were responsible for engraftment 
Citation: Danby R, Rocha V (2014) Current Strategies to Improve Engraftment in Cord Blood Transplantation. J Stem Cell Res Ther 4: 172. doi:10.4172/2157-7633.1000172

and that ex vivo fucosylation improved UCB engraftment rates. These pre-clinical studies show interesting results and, as such, further investigation is warranted to determine whether these techniques can improve HSC engraftment in a cost-effective way and without adversely affecting long-term results. A multicenter, non-randomized phase II trial of inhibition of CD26 peptidase using Sitagliptin to enhance engraftment after UCBT in adults with hematological malignancy is currently in process (ClinicalTrials.gov NCT01720264). Similarly, the MD Anderson group is recruiting to a non-randomized phase II study of $\mathrm{CB}$ fucosylation to enhance homing and engraftment in patients with hematological malignancies (ClinicalTrials.gov NCT01471067).

\section{Growth factors}

Although many UCBT protocols use in vivo recombinant granulocyte colony stimulating factor (G-CSF) to aid myeloid engraftment, relatively little published data has formerly examined its effect. In 102 MAC single UCBT, use of G-CSF was associated with a trend $(P=0.09)$ towards improved neutrophil recovery. The cumulative incidence of neutrophil recovery by day 42 was $90 \%$ ( $95 \%$ CI $84-97 \%$ ) with a median of 21 days (range, 9-54 days) for G-CSF treated patients compared to $80 \%$ (95\% CI 60-100\%) with median of 31 days (range, 17-45 days) for no G-CSF. However, use of G-CSF did not remain significant in multivariate analysis. In a larger study in 2004, Gluckman et al. [124] analyzed 550 UCBTs in patients with hematological malignancy in which G-CSF was given to $60 \%$ of patients. As well as cell dose and HLA-matching, early use of G-CSF was independently associated with improved neutrophil recovery (HR 1.66 (95\% CI, 1.34-2.05), $P<0.0001$ ). There have also been occasional case reports on the successful use of combined G-CSF and recombinant in vivo stem cell factor (SCF) post-UCBT. However, further studies will be required to determine if there is any benefit to this approach. In relation to platelet recovery, there remains much interest in the use of thrombopoietin agonists to improve engraftment. Thrombopoietin (TPO) is produced by the liver and kidneys and regulates the production of platelets by stimulating megakaryocyte production and differentiation within the bone marrow. It also has an important role in regulation and proliferation of HSC and other multipotent HPC and has been used in ex vivo expansion of CB [89,125-127]. Although phase II/III clinical trials of recombinant TPO in thrombocytopenic disorders produced disappointing results due to the development of TPO specific antibodies, there have been more interesting results with peptide mimetics (Romiplostim) and non-peptide small molecule TPO receptor (c-Mpl) agonists (Eltrombopag) [128-130]. In NOD/ SCID mouse xeno transplant models, Eltrombopag increased the expansion of human $\mathrm{UCB} \mathrm{CD} 34^{+}, \mathrm{CD} 45^{+}$, and $\mathrm{CD} 41^{+}$cells with an associated increase in PB platelets and white cells [131]. A phase I study of Eltrombopag in HSCT (non-UCB) has shown good safety and tolerability [132]. Consequently, there are now several early phase trials of Eltrombopag currently recruiting in both adult and pediatric UCBT (ClinicalTrials.gov NCT01927731; NCT01757145; NCT01940562).

\section{Co-transplantation of accessory cells}

Mesenchymal stem cells: Mesenchymal stem cells (MSC) are multipotent undifferentiated stromal cells with capacity to self-renew and/or differentiate into mesenchymal cells including chondrocytes, osteocytes, adipocytes, cardiomyocytes, and neurons. They are present in $\mathrm{PB}, \mathrm{BM}, \mathrm{UCB}$, and non-hematopoietic tissues including fat, muscle, and UC connective tissue, e.g. Wharton's jelly, although their exact function in vivo remains unclear. MSC are a heterogeneous population that lack hematopoietic markers (CD45/CD34/CD14) but express the antigens SH-3/SH-4 (CD73), Thy-1 (CD90), and Endoglin
(CD105) [133]. However, there is considerable phenotypic variation between MSC obtained from different sources and there is no single unifying marker allowing specific isolation of these cells. MSC have low immunogenicity and potent immunosuppressive function that may be useful for improving engraftment and preventing GvHD. They do not express class II MHC molecules or co-stimulatory molecules and, thus, do not elicit allo-antigenic responses. They can also suppress $\mathrm{T}$ and NK-cell proliferation, cytokine secretion, and B-cell function [134-136]. Functional mechanisms include cell-contact dependent and independent responses including IL-10, TGF $\beta$, nitric oxide (NO), and induction of regulatory $\mathrm{T}$ cells [136-138].

In relation to $\mathrm{UCBT}$, pre-clinical murine studies demonstrated that co-transplantation of MSC with $\mathrm{CB}$ CD $34^{+}$cells in NOD/SCID mice improved engraftment [139-141]. In addition, UC MSC support ex vivo expansion of CB HSC in long-term cultures [142]. In 2009, MacMillan and colleagues performed a phase I/II study of ex vivo expanded haploidentical BM-derived MSC in pediatric patients with leukemia receiving a MAC unrelated UCBT [143]. Eight patients received MSC (median dose $2.1 \times 10^{6} / \mathrm{kg}$ (range, $\left.0.9-5.0\right)$ ) in addition to UCB (median TNC $3.1 \times 10^{7} / \mathrm{kg}$ (range, 2.0-12.4)), with three patients receiving an additional infusion of MSC on day 21. There were no harmful side effects related to infusion of the MSC. All patients achieved neutrophil engraftment at a median time 19 days (range, 9-28 days). Six patients achieved platelet engraftment at a median of 53 days (range, 36-98 days). Rates of engraftment, GvHD, and survival were comparable to equivalent historical group demonstrating the safety and feasibility of this approach. In a similar pilot study, nine patients received a MAC UCBT with co-infusion of BM-derived MSC and T-depleted HSC from a third party donor [144]. All patients achieved neutrophil engraftment with a median time to recovery of 12 days (range, 10-31 days) and full CB chimerism at a median of 51 days (range, 20-186 days). The maximum cumulative incidence of platelet engraftment was $88 \%$ (95\% CI, 70$100 \%$ ) at a median of 32 days (range, 13-97 days). However, there was no difference in the rate of engraftment compared to a control group of 46 transplants from the same center not receiving MSC. Bernardo et al. [145] reported similar findings in 13 pediatric UCB transplants using paternal MSC with no difference in engraftment or rates of rejection compared to 39 matched historical controls. Recently, a phase I/II study of UCB transplants with UC-derived MSC has been performed [146]. Five patients received ex vivo expanded MSC obtained from Wharton's jelly without any adverse events. Neutrophil engraftment (median 11 days (range, 7-13 days)) and platelet engraftment (median 32 days (range, 22-41 days)) were significantly faster than in nine control patients not receiving MSC. These early studies demonstrate that coinfusion of MSC with UCBT can be performed safely. However, the full implications for engraftment and immune reconstitution still remain unclear and further prospective studies are required.

Regulatory T cells: The human immune system maintains the delicate equilibrium between protecting the body from harmful pathogens ('non-self) while being unresponsive to self-antigens ('self-tolerance'). This is achieved through passive central tolerance ('positive' and 'negative' selection of T-cells in the thymus) and peripheral immune tolerance in which specific cells ("suppressor cells") suppress autoreactive clones using dominant mechanisms. Of these, regulatory T cells (Tregs) are the best described. In 1995, Sakaguchi et al. [147] identified a population of $\mathrm{CD}^{+} \mathrm{T}$ cells expressing the IL-2 receptor alpha chain $(\mathrm{CD} 25)$. When $\mathrm{CD}^{+} \mathrm{CD} 25^{-}$cells, isolated from $\mathrm{BALB} / \mathrm{c} \mathrm{nu} /{ }^{+}$mice, were transferred into $\mathrm{BALB} / \mathrm{b} \mathrm{nu} / \mathrm{nu}$ mice, they induced a widespread autoimmune disease, which could be prevented by the co-transfer of donor $\mathrm{CD} 4{ }^{+} \mathrm{CD} 25^{+}$cells. The $\mathrm{CD} 4{ }^{+} \mathrm{CD} 25^{+} \mathrm{T}$-cells 
became known as Tregs and, in 2001, human $\mathrm{CD} 4^{+} \mathrm{CD} 25^{+}$Tregs were first described $[148,149]$. In 2003, the transcription factor forkhead box P3 (Foxp3) was found to be specifically expressed in Tregs and is now thought to be the master regulator of Treg differentiation and function $[150,151]$. Tregs exert their immune tolerance by inhibiting proliferation and cytokine secretion of $\mathrm{T}, \mathrm{B}, \mathrm{NK}, \mathrm{NK}-\mathrm{T}$, and antigen presenting cells. Proposed functional mechanisms include cell contact independent mechanisms, such as sequestration of IL-2 and production of inhibitory cytokines (IL-10, IL-35), and cell contact dependent mechanisms, including CTLA-4, cell surface TGF $\beta$, and granzyme mediated apoptosis [152].

There has been particular interest in Tregs in the setting of allogeneic HSCT. In mice, co-transfer $(1: 1)$ of $\mathrm{CD} 4^{+} \mathrm{CD} 25^{+}$Tregs with $\mathrm{CD} 4{ }^{+} \mathrm{CD} 25$ effector $\mathrm{T}$ cells from $\mathrm{C} 57 \mathrm{BL} / 6$ mice into MHC mismatched $\mathrm{BALB} / \mathrm{c}$ mice prevented the lethal GvHD seen with the transfer of $\mathrm{CD} 4^{+} \mathrm{CD} 25^{-}$effector $\mathrm{T}$ cells alone [153]. Furthermore, $\mathrm{CD} 4^{+} \mathrm{CD} 25^{+}$ Tregs co-transferred with $\mathrm{CD} 4^{+} \mathrm{CD} 25^{-}$conventional $\mathrm{T}$ cells to an $\mathrm{MHC}$ mismatched mouse with leukemia were able to prevent GvHD but did not prevent an effective GvT response [154]. In human allogeneic HSCT, reduced numbers of $\mathrm{CD} 4^{+} \mathrm{CD} 25^{\text {high }}$ cells, $\mathrm{CD} 4^{+} \mathrm{FOXP} 3^{+}$cells, $\mathrm{CD}^{+} \mathrm{CD} 25^{\text {high }} \mathrm{FOXP}^{+}$cells, or FOXP3 mRNA in blood and tissues have been observed in patients with GvHD [155-160]. Similarly, low numbers of $\mathrm{CD}^{+} \mathrm{FOXP}^{+}$Tregs in $\mathrm{PBSCH}$ was an independent predictor of acute GvHD in MAC transplants [161,162]. A low graft CD3/Treg ratio $(<36)$ in MAC T-replete PBSC transplants was also found to be an independent predictor of improved NRM and overall survival $[163,164]$. UCB also contains $\mathrm{CD}^{+} \mathrm{CD} 25^{+}$Tregs with the proportion of cells inversely correlating with gestational age up to the levels found in adult $\mathrm{PB}$ ( $2 \%$ to $5 \%$ of $\mathrm{CD} 4^{+} \mathrm{T}$ cells) [165]. In contrast to adult $\mathrm{PB}$, the majority of $\mathrm{CB}$ Tregs expresses naïve markers and does not initially show suppressor activity $[166,167]$. However, upon antigenic stimulation, these cells upregulate CD25, CTLA-4, and FOXP3, proliferating with a higher expansion capacity compared to adult Tregs and posses potent suppressive activity [166,167].

In light of these observations, using Tregs in allogeneic HSCT may be a promising strategy to promote engraftment and immune reconstitution and prevent GvHD. Two clinical trials of adoptive transfer of ex-vivo isolated Tregs have been performed in humans. The first was a phase I study in which patients with a high risk of relapse were pre-emptively given up to $5 \times 10^{6} / \mathrm{kg}$ Tregs prior to donor lymphocyte infusions [168]. In nine patients, there were no adverse events related to the Tregs. In the second study, 28 HLAhaploidentical transplants were given $2-4 \times 10^{6} / \mathrm{kg}$ isolated Tregs $\left(50 \% \mathrm{FOXP}^{+}\right)$four days prior to receiving $\mathrm{CD}^{+} 4^{+}$cells and $0.5-2.0$ $\times 10^{6} / \mathrm{kg}$ conventional $\mathrm{T}$ cells [169]. The administration of Tregs into a lymphopenic environment was to allow pre-activation and homeostatic expansion of Tregs in vivo [170]. Despite the absence of other immunosuppression, only two patients developed grade II-IV acute GvHD. In the context of UCBT, Treg isolation has been more problematic due to the low TNC number per CBU. Therefore, in vitro expansion is necessary in which Tregs are expanded using antiCD3/CD28 stimulation and IL-2. The mTOR inhibitor, Rapamycin, may enhance Treg expansion further by preventing proliferation of conventional T cells whilst allowing expansion of Tregs [171-173]. To date, only Brunstein et al. [174] have reported results using expanded human Tregs. 23 double UCBT patients were given Tregs at a dose of $1-30 \times 10^{5} / \mathrm{kg}$ on day one, with 13 of these receiving an additional dose of $30 \times 10^{5} / \mathrm{kg}$ on day 15 . Tregs were obtained by CD25 bead isolation from third party UCB and expanded with CD3/CD28 beads and IL-2 (300 IU/ml) for 18 days. There were no reported adverse events. The cumulative incidence of sustained neutrophil engraftment was $87 \%$ (95\% CI, 70-97\%) and the incidence of platelet recovery by day 100 was $74 \%$ (95\% CI, 51-97\%) at a median of 46 days (range, $27-87$ days). When compared with 108 historical controls, donor engraftment was not adversely affected by the co-infusion of Tregs, although the study was not designed to show improved engraftment. These reports are, therefore, the first tentative steps toward Treg cellular therapies and highlight the feasibility of such approaches. The effect of Tregs on UCB engraftment remains to be elucidated. However, Fujisaki et al. [175] demonstrated in mouse models using high resolution in-vivo imaging, that allogeneic HSC co-localize with Foxp3(+) Tregs on the endosteal surface of the bone, potentially forming an immune privileged site for engraftment. Furthermore, depletion of Tregs resulted in loss of the allogeneic HSC. Continued research into the impact of Tregs on UCBT and engraftment is therefore required.

\section{Conclusion}

In recent years, UCB has remained an important source of HSC for those patients requiring HSC transplantation but lacking a suitable sibling or unrelated donor. As our combined knowledge and experience of UCB transplantation has steadily increased, clinical outcomes after UCB transplantation have continued to advance. In particular, the incidence and speed of UCB engraftment has improved, mainly due to the use of higher cell doses, improved HLA-matching, better supportive care and greater center experience. However, as our basic understanding of CB biology, HSCs, and hematopoiesis progresses, further clinical improvements can be made. New strategies such as $\mathrm{CB}$ expansion, improved homing and delivery of CB HSC, and use of third-party supportive cells all show promising developments in early trials. Prospective clinical studies are in progress to ascertain whether these techniques will further enhance engraftment and determine what impact this will have on morbidity and mortality following UCBT. Combined with new methods to improve immune reconstitution, it is anticipated that, for specific patients, UCB transplantation will continue to have a crucial role in the management of hematological disorders.

\section{Acknowledgements}

The authors would like to thank NHS Blood and Transplant (UK) and the National Institute for Health Research (NIHR) Biomedical Research Centre for their support.

\section{References}

1. Ballen KK, Gluckman E, Broxmeyer HE (2013) Umbilical cord blood transplantation: the first 25 years and beyond. Blood 122: 491-498.

2. Majhail NS, Nayyar S, Santibañez ME, Murphy EA, Denzen EM (2012) Racia disparities in hematopoietic cell transplantation in the United States. Bone Marrow Transplant 47: 1385-1390.

3. Bone Marrow Donors Worldwide (2014) [10/01/2014].

4. Gluckman E, Broxmeyer HA, Auerbach AD, Friedman HS, Douglas GW, et al. (1989) Hematopoietic reconstitution in a patient with Fanconi's anemia by means of umbilical-cord blood from an HLA-identical sibling. N Engl J Med 321: 1174-1178.

5. Gluckman E, Rocha V, Boyer-Chammard A, Locatelli F, Arcese W, et al (1997) Outcome of cord-blood transplantation from related and unrelated donors. Eurocord Transplant Group and the European Blood and Marrow Transplantation Group. The New England journal of medicine 337: 373-381.

6. Rocha V, Cornish J, Sievers EL, Filipovich A, Locatelli F, et al. (2001) Comparison of outcomes of unrelated bone marrow and umbilical cord blood transplants in children with acute leukemia. Blood 97: 2962-2971.

7. Rocha V, Labopin M, Sanz G, Arcese W, Schwerdtfeger R, et al. (2004) Transplants of umbilical-cord blood or bone marrow from unrelated donors in adults with acute leukemia. N Engl J Med 351: 2276-2285. 
Citation: Danby R, Rocha V (2014) Current Strategies to Improve Engraftment in Cord Blood Transplantation. J Stem Cell Res Ther 4: 172 doi:10.4172/2157-7633.1000172

8. Rocha V, Gluckman E; Eurocord-Netcord registry and European Blood and Marrow Transplant group (2009) Improving outcomes of cord blood transplantation: HLA matching, cell dose and other graft- and transplantationrelated factors. $\mathrm{Br} \mathrm{J}$ Haematol 147: 262-274.

9. Rubinstein P, Carrier C, Scaradavou A, Kurtzberg J, Adamson J, et al. (1998) Outcomes among 562 recipients of placental-blood transplants from unrelated donors. N Engl J Med 339: 1565-1577.

10. Laughlin MJ, Eapen M, Rubinstein P, Wagner JE, Zhang MJ, et al. (2004) Outcomes after transplantation of cord blood or bone marrow from unrelated donors in adults with leukemia. N Engl J Med 351: 2265-2275.

11. Szabolcs $P$, Niedzwiecki D (2007) Immune reconstitution after unrelated cord blood transplantation. Cytotherapy 9: 111-122.

12. Bender JG, Unverzagt K, Walker DE, Lee W, Smith S, et al. (1994) Phenotypic analysis and characterization of CD34+ cells from normal human bone marrow, cord blood, peripheral blood, and mobilized peripheral blood from patients undergoing autologous stem cell transplantation. Clinical immunology and Immunopathology 70: 10-18.

13. Kaminski BA, Kadereit S, Miller RE, Leahy P, Stein KR, et al. (2003) Reduced expression of NFAT-associated genes in UCB versus adult CD4+ T lymphocytes during primary stimulation. Blood 102: 4608-4617.

14. Chen L, Cohen AC, Lewis DB (2006) Impaired allogeneic activation and T-helper 1 differentiation of human cord blood naive CD4 T cells. Biology of blood and marrow transplantation: journal of the American Society for Blood and Marrow Transplantation 12: 160-171.

15. Kim YJ, Broxmeyer HE (2011) Immune regulatory cells in umbilical cord blood and their potential roles in transplantation tolerance. Crit Rev OncolHematol 79: 112-126.

16. vanHennik PB, de Koning AE, Ploemacher RE (1999) Seeding efficiency of primitive human hematopoietic cells in nonobese diabetic/severe combined immune deficiency mice: implications for stem cell frequency assessment. Blood 94: 3055-3061.

17. Cashman JD, Eaves CJ (2000) High marrow seeding efficiency of human lymphomyeloid repopulating cells in irradiated NOD/SCID mice. Blood 96: 3979-3981.

18. Sahin AO, Buitenhuis M (2012) Molecular mechanisms underlying adhesion and migration of hematopoietic stem cells. Cell AdhMigr 6: 39-48.

19. Voermans C, Rood PM, Hordijk PL, Gerritsen WR, van der Schoot CE (2000) Adhesion molecules involved in transendothelial migration of human hematopoietic progenitor cells. Stem Cells 18: 435-443.

20. vanBuul JD, Voermans C, van den Berg V, Anthony EC, Mul FP, et al. (2002) Migration of human hematopoietic progenitor cells across bone marrow endothelium is regulated by vascular endothelial cadherin. Journal of immunology 168: 588-596.

21. Nilsson L, Astrand-Grundstrom I, Arvidsson I, Jacobsson B, Hellstrom-Lindberg $\mathrm{E}$, et al. (2000) Isolation and characterization of hematopoietic progenitor/stem cells in 5q-deleted myelodysplastic syndromes: evidence for involvement at the hematopoietic stem cell level. Blood 96: 2012-2021.

22. Aiuti A, Webb IJ, Bleul C, Springer T, Gutierrez-Ramos JC (1997) The chemokine SDF-1 is a chemoattractant for human CD34+ hematopoietic progenitor cells and provides a new mechanism to explain the mobilization of CD34+ progenitors to peripheral blood. The Journal of experimental medicine 185: $111-120$.

23. Liesveld JL, Rosell K, Panoskaltsis N, Belanger T, Harbol A, et al. (2001) Response of human $\mathrm{CD} 34+$ cells to $\mathrm{CXC}, \mathrm{CC}$, and $\mathrm{CX} 3 \mathrm{C}$ chemokines: implications for cell migration and activation. J Hematother Stem Cell Res 10: 643-655.

24. Peled A, Petit I, Kollet O, Magid M, Ponomaryov T, et al. (1999) Dependence of human stem cell engraftment and repopulation of NOD/SCID mice on CXCR4. Science 283: 845-848.

25. Ponomaryov T, Peled A, Petit I, Taichman RS, Habler L, et al. (2000) Induction of the chemokine stromal-derived factor-1 following DNA damage improves human stem cell function. J Clin Invest 106: 1331-1339.

26. Peled A, Kollet O, Ponomaryov T, Petit I, Franitza S, et al. (2000) The chemokine SDF-1 activates the integrins LFA-1, VLA-4, and VLA-5 on immature human CD34(+) cells: role in transendothelial/stromal migration and engraftment of NOD/SCID mice. Blood 95: 3289-3296.
27. Lataillade JJ, Clay D, Dupuy C, Rigal S, Jasmin C, et al. (2000) Chemokine SDF-1 enhances circulating CD34(+) cell proliferation in synergy with cytokines: possible role in progenitor survival. Blood 95: 756-768.

28. Broxmeyer HE, Kohli L, Kim CH, Lee Y, Mantel C, et al. (2003) Stromal cellderived factor-1/CXCL12 directly enhances survival/antiapoptosis of myeloid progenitor cells through CXCR4 and $\mathrm{G}($ alpha)i proteins and enhances engraftment of competitive, repopulating stem cells. Journal of leukocyte biology 73: 630-638.

29. Arber C, Halter J, Stern M, Rovo A, Gratwohl A, et al. (2011) Graft source determines human hematopoietic progenitor distribution pattern within the CD34(+) compartment. Bone marrow transplantation 46: 650-658.

30. Gomi S, Hasegawa S, Dan K, Wakabayashi I (1997) A comparative analysis of the transplant potential of umbilical cord blood versus mobilized peripheral blood stem cells. Nihon IkaDaigakuZasshi 64: 307-313.

31. Wang JC, Doedens M, Dick JE (1997) Primitive human hematopoietic cells are enriched in cord blood compared with adult bone marrow or mobilized peripheral blood as measured by the quantitative in vivo SCID-repopulating cell assay. Blood 89: 3919-3924.

32. Lu L, Xiao M, Shen RN, Grigsby S, Broxmeyer HE (1993) Enrichment characterization, and responsiveness of single primitive CD34 human umbilical cord blood hematopoietic progenitors with high proliferative and replating potential. Blood 81: 41-48.

33. Piacibello W, Sanavio F, Severino A, Danè A, Gammaitoni L, et al. (1999) Engraftment in nonobese diabetic severe combined immunodeficient mice of human CD34(+) cord blood cells after ex vivo expansion: evidence for the amplification and self-renewal of repopulating stem cells. Blood 93: 3736-3749.

34. Theunissen K, Verfaillie CM (2005) A multifactorial analysis of umbilical cord blood, adult bone marrow and mobilized peripheral blood progenitors using the improved ML-IC assay. ExpHematol 33: 165-172.

35. Brown JA, Boussiotis VA (2008) Umbilical cord blood transplantation: basic biology and clinical challenges to immune reconstitution. Clinlmmunol 127: 286-297.

36. Roy V, Verfaillie CM (1999) Expression and function of cell adhesion molecules on fetal liver, cord blood and bone marrow hematopoietic progenitors: implications for anatomical localization and developmental stage specific regulation of hematopoiesis. Experimental hematology 27: 302-312.

37. Ng YY, van Kessel B, Lokhorst HM, Baert MR, van den Burg CM, et al. (2004) Gene-expression profiling of CD34+ cells from various hematopoietic stem-cell sources reveals functional differences in stem-cell activity. J LeukocBiol 75: 314-323.

38. Panepucci RA, Calado RT, Rocha V, Proto-Siqueira R, Silva WA Jr, et al (2007) Higher expression of transcription targets and components of the nuclear factor-kappaB pathway is a distinctive feature of umbilical cord blood CD34+ precursors. Stem Cells 25: 189-196.

39. Gaddy J, Broxmeyer HE (1997) Cord blood CD16+56- cells with low lytic activity are possible precursors of mature natural killer cells. Cell Immunol 180: 132-142.

40. Seggewiss R, Einsele H (2010) Immune reconstitution after allogeneic transplantation and expanding options for immunomodulation: an update. Blood 115: 3861-3868

41. Ruggeri A, Peffault de Latour R, Carmagnat M, Clave E, Douay C, et al. (2011) Outcomes, infections, and immune reconstitution after double cord blood transplantation in patients with high-risk hematological diseases. Transplan infectious disease : an official journal of the Transplantation Society 13: 456465.

42. Ruggeri A, Sanz G, Bittencourt H, Sanz J, Rambaldi A, et al. (2013) Comparison of outcomes after single or double cord blood transplantation in adults with acute leukemia using different types of myeloablative conditioning regimen, a retrospective study on behalf of Eurocord and the Acute Leukemia Working Party of EBMT. Leukemia

43. Parody R, Martino R, Rovira M, Vazquez L, Vazquez MJ, et al. (2006) Severe infections after unrelated donor allogeneic hematopoietic stem cell transplantation in adults: comparison of cord blood transplantation with peripheral blood and bone marrow transplantation. Biology of blood and marrow transplantation: journal of the American Society for Blood and Marrow Transplantation 12: 734-748.

44. Barker JN, Hough RE, van Burik JA, DeFor TE, MacMillan ML, et al. (2005) 
Citation: Danby R, Rocha V (2014) Current Strategies to Improve Engraftment in Cord Blood Transplantation. J Stem Cell Res Ther 4: 172. doi:10.4172/2157-7633.1000172

Page 12 of 15

Serious infections after unrelated donor transplantation in 136 children: impact of stem cell source. Biology of blood and marrow transplantation: journal of the American Society for Blood and Marrow Transplantation 11: 362-370.

45. Gluckman E, Rocha V, Arcese W, Michel G, Sanz G, et al. (2004) Factors associated with outcomes of unrelated cord blood transplant: guidelines for donor choice. ExpHematol 32: 397-407.

46. Eapen M, Rubinstein P, Zhang MJ, Stevens C, Kurtzberg J, et al. (2007) Outcomes of transplantation of unrelated donor umbilical cord blood and bone marrow in children with acute leukaemia: a comparison study. Lancet 369: 1947-1954.

47. Barker JN, Scaradavou A, Stevens CE (2010) Combined effect of total nucleated cell dose and HLA match on transplantation outcome in 1061 cord blood recipients with hematologic malignancies. Blood 115: 1843-1849.

48. Eapen M, Klein JP, Sanz GF, Spellman S, Ruggeri A, et al. (2011) Effect of donor-recipient HLA matching at HLA A, B, C, and DRB1 on outcomes after umbilical-cord blood transplantation for leukaemia and myelodysplastic syndrome: a retrospective analysis. The lancet oncology 12: 1214-1221.

49. Kogler G, Enczmann J, Rocha V, Gluckman E, Wernet P (2005) High-resolution HLA typing by sequencing for HLA-A, -B, -C, -DR, -DQ in 122 unrelated cord blood/patient pair transplants hardly improves long-term clinical outcome. Bone marrow transplantation 36: 1033-1041.

50. Delaney M, Cutler CS, Haspel RL, Yeap BY, McAfee SL, et al. (2009) Highresolution HLA matching in double-umbilical-cord-blood reduced-intensity transplantation in adults. Transfusion 49: 995-1002.

51. Eapen M, Klein JP, Ruggeri A, Spellman S, Lee SJ, et al. (2014) Impact of allele-level HLA matching on outcomes after myeloablative single unit umbilical cord blood transplantation for hematologic malignancy. Blood 123: 133-140.

52. Petropoulou $A D$, Rocha $V$ (2011) Risk factors and options to improve engraftment in unrelated cord blood transplantation. Stem Cells Int 2011: 610514

53. Brunstein CG, Barker JN, Weisdorf DJ, DeFor TE, Miller JS, et al. (2007) Umbilical cord blood transplantation after nonmyeloablative conditioning: impact on transplantation outcomes in 110 adults with hematologic disease. Blood 110: 3064-3070.

54. Kindwall-Keller TL, Hegerfeldt $Y$, Meyerson HJ, Margevicius S, Fu P, et al. (2012) Prospective study of one- vs two-unit umbilical cord blood transplantation following reduced intensity conditioning in adults with hematological malignancies. Bone marrow transplantation 47: 924-933.

55. Sandmaier BM, Mackinnon S, Childs RW (2007) Reduced intensity conditioning for allogeneic hematopoietic cell transplantation: current perspectives. Biology of blood and marrow transplantation: journal of the American Society for Blood and Marrow Transplantation 13: 87-97.

56. Barker JN, Weisdorf DJ, DeFor TE, Blazar BR, Miller JS, et al. (2003) Rapid and complete donor chimerism in adult recipients of unrelated donor umbilical cord blood transplantation after reduced-intensity conditioning. Blood 102 1915-1919.

57. Chen YB, Aldridge J, Kim HT, Ballen KK, Cutler C, et al. (2012) Reducedintensity conditioning stem cell transplantation: comparison of double umbilical cord blood and unrelated donor grafts. Biology of blood and marrow transplantation: journal of the American Society for Blood and Marrow Transplantation 18: 805-812.

58. Brunstein CG, Eapen M, Ahn KW, Appelbaum FR, Ballen KK, et al. (2012) Reduced-intensity conditioning transplantation in acute leukemia: the effect of source of unrelated donor stem cells on outcomes. Blood 119: 5591-5598.

59. Rodrigues CA, Rocha V, Dreger P, Brunstein CG, Sengeloev H, et al. (2013) Alternative donor hematopoietic stem cell transplantation for mature lymphoid malignancies after reduced-intensity conditioning regimen: similar outcomes with umbilical cord blood and unrelated donor peripheral blood. Haematologica 99: 370-377.

60. Peffault de Latour R, Brunstein CG, Porcher R, Chevallier P, Robin M, et al. (2013) Similar overall survival using sibling, unrelated donor, and cord blood grafts after reduced-intensity conditioning for older patients with acute myelogenous leukemia. Biology of blood and marrow transplantation: journal of the American Society for Blood and Marrow Transplantation 19: 1355-1360.

61. Narimatsu H, Watanabe M, Kohno A, Sugimoto K, Kuwatsuka Y, et al. (2008) High incidence of graft failure in unrelated cord blood transplantation using a reduced-intensity preparative regimen consisting of fludarabine and melphalan. Bone marrow transplantation 41: 753-756

62. Horwitz ME, Morris A, Gasparetto C, Sullivan K, Long G, et al. (2008) Myeloablative intravenous busulfan/fludarabine conditioning does not facilitate reliable engraftment of dual umbilical cord blood grafts in adult recipients. Biology of blood and marrow transplantation: journal of the American Society for Blood and Marrow Transplantation 14: 591-594.

63. Cutler C, Ballen K (2009) Reduced-intensity conditioning and umbilical cord blood transplantation in adults. Bone Marrow Transplant 44: 667-671.

64. Oran B, Wagner JE, DeFor TE, Weisdorf DJ, Brunstein CG (2011) Effect of conditioning regimen intensity on acute myeloid leukemia outcomes after umbilical cord blood transplantation. Biology of blood and marrow transplantation: journal of the American Society for Blood and Marrow Transplantation 17: 1327-1334.

65. Geyer MB, Jacobson JS, Freedman J, George D, Moore V, et al. (2011) A comparison of immune reconstitution and graft-versus-host disease following myeloablative conditioning versus reduced toxicity conditioning and umbilical cord blood transplantation in paediatric recipients. British journal of haematology 155: 218-234

66. Nabhan S RV, Chevret S (2008) Influence of myeloablative conditioning regimens on outcomes after single unrelated cord blood transplantation for adults with leukemia: analysis on behalf of Eurocord-EBMT-Netcord. Blood 112

67. Gluckman E, Rocha V, lonescu I, Bierings M, Harris RE, et al. (2007) Results of unrelated cord blood transplant in fanconi anemia patients: risk factor analysis for engraftment and survival. Biology of blood and marrow transplantation: journal of the American Society for Blood and Marrow Transplantation 13 1073-1082.

68. Storb R, Deeg HJ, Pepe M, Appelbaum F, Anasetti C, et al. (1989) Methotrexate and cyclosporine versus cyclosporine alone for prophylaxis of graft-versus-hos disease in patients given HLA-identical marrow grafts for leukemia: long-term follow-up of a controlled trial. Blood 73: 1729-1734.

69. Davies SM, Kollman C, Anasetti C, Antin JH, Gajewski J, et al. (2000) Engraftment and survival after unrelated-donor bone marrow transplantation: a report from the national marrow donor program. Blood 96: 4096-4102.

70. Locatelli F, Rocha V, Reed W, Bernaudin F, Ertem M, et al. (2003) Related umbilical cord blood transplantation in patients with thalassemia and sickle cell disease. Blood 101: 2137-2143.

71. Narimatsu H, Terakura S, Matsuo K, Oba T, Uchida T, et al. (2007) Short-term methotrexate could reduce early immune reactions and improve outcomes in umbilical cord blood transplantation for adults. Bone Marrow Transplant 39 : 31-39.

72. Atsuta Y, Suzuki R, Nagamura-Inoue T, Taniguchi S, Takahashi S, et al. (2009) Disease-specific analyses of unrelated cord blood transplantation compared with unrelated bone marrow transplantation in adult patients with acute leukemia. Blood 113: 1631-1638.

73. Okamura A, Shimoyama M, Ishii S, Wakahashi K, Asada N, et al. (2011) Delayed neutrophil engraftment in cord blood transplantation with intensive administration of mycophenolatemofetil for GVHD prophylaxis. Bone Marrow Transplant 46: 148-149.

74. Sanz J, Picardi A, Hernandez Boluda JC, Martin C, Ferra C, et al. (2013) Impact of graft-versus-host disease prophylaxis on outcomes after myeloablative single-unit umbilical cord blood transplantation. Biology of blood and marrow transplantation: journal of the American Society for Blood and Marrow Transplantation 19: 1387-1392.

75. Broxmeyer HE, Cooper S, Hass DM, Hathaway JK, Stehman FB, et al. (2009) Experimental basis of cord blood transplantation. Bone Marrow Transplant 44 627-633.

76. Louis I, Wagner E, Dieng MM, Morin H, Champagne MA, et al. (2012) Impact of storage temperature and processing delays on cord blood quality: discrepancy between functional in vitro and in vivo assays. Transfusion 52: 2401-2405.

77. Solves P, Planelles D, Mirabet V, Blanquer A, Carbonell-Uberos F (2013) Qualitative and quantitative cell recovery in umbilical cord blood processed by two automated devices in routine cord blood banking: a comparative study. Blood transfusion = Trasfusione del sangue 11: 405-411

78. McManus MP, Wang L, Calder C, Manes B, Evans M, et al. (2012) Comparison of pre-cryopreserved and post-thaw-and-wash-nucleated cell count on major 
Citation: Danby R, Rocha V (2014) Current Strategies to Improve Engraftment in Cord Blood Transplantation. J Stem Cell Res Ther 4: 172 doi:10.4172/2157-7633.1000172

outcomes following unrelated cord blood transplant in children. Pediatric transplantation 16: 438-442.

79. Barker JN, Weisdorf DJ, Wagner JE (2001) Creation of a double chimera after the transplantation of umbilical-cord blood from two partially matched unrelated donors. N Engl J Med 344: 1870-1871.

80. Barker JN, Weisdorf DJ, DeFor TE, Blazar BR, McGlave PB, et al. (2005) Transplantation of 2 partially HLA-matched umbilical cord blood units to enhance engraftment in adults with hematologic malignancy. Blood 105: 13431347.

81. Brunstein CG, Gutman JA, Weisdorf DJ, Woolfrey AE, Defor TE, et al. (2010) Allogeneic hematopoietic cell transplantation for hematologic malignancy: relative risks and benefits of double umbilical cord blood. Blood 116: 46934699

82. Somers JA, Brand A, van Hensbergen Y, Mulder A, Oudshoorn M, et al. (2013) Double umbilical cord blood transplantation: a study of early engraftment kinetics in leukocyte subsets using HLA-specific monoclonal antibodies. Biology of blood and marrow transplantation: journal of the American Society for Blood and Marrow Transplantation 19: 266-273.

83. Verneris MR, Brunstein CG, Barker J, MacMillan ML, DeFor T, et al. (2009) Relapse risk after umbilical cord blood transplantation: enhanced graft-versusleukemia effect in recipients of 2 units. Blood 114: 4293-4299.

84. Rocha V, Broxmeyer HE (2010) New approaches for improving engraftment after cord blood transplantation. Biol Blood Marrow Transplant 16: S126-132.

85. MacMillan ML, Weisdorf DJ, Brunstein CG, Cao Q, DeFor TE, et al. (2009) Acute graft-versus-host disease after unrelated donor umbilical cord blood transplantation: analysis of risk factors. Blood 113: 2410-2415.

86. Wallet HL, Sobh M, Morisset S, Robin M, Fegueux N, et al. (2013) Double umbilical cord blood transplantation for hematological malignancies: a longterm analysis from the SFGM-TC registry. ExpHematol 41: 924-933.

87. de Lima M, McNiece I, Robinson SN, Munsell M, Eapen M, et al. (2012) Cordblood engraftment with ex vivo mesenchymal-cell coculture. N Engl J Med 367 2305-2315.

88. Shpall EJ, Quinones R, Giller R, Zeng C, Baron AE, et al. (2002) Transplantation of ex vivo expanded cord blood. Biol Blood Marrow Transplant 8: 368-376

89. Levac K, Karanu F, Bhatia M (2005) Identification of growth factor conditions that reduce ex vivo cord blood progenitor expansion but do not alter human repopulating cell function in vivo. Haematologica 90: 166-172

90. Bordeaux-Rego P, Luzo A, Costa FF, Olalla Saad ST, Crosara-Alberto DP (2010) Both interleukin-3 and interleukin-6 are necessary for better ex vivo expansion of CD133+ cells from umbilical cord blood. Stem Cells Dev 19: 413422

91. de Lima M, McMannis J, Gee A, Komanduri K, Couriel D, et al. (2008) Transplantation of ex vivo expanded cord blood cells using the copper chelatortetraethylenepentamine: a phase I/II clinical trial. Bone Marrow Transplant 41: 771-778.

92. Delaney C, Heimfeld S, Brashem-Stein C, Voorhies H, Manger RL, et al. (2010) Notch-mediated expansion of human cord blood progenitor cells capable of rapid myeloid reconstitution. Nature medicine 16: 232-236.

93. Robinson S, Niu T, de Lima M, Ng J, Yang H, et al. (2005) Ex vivo expansion of umbilical cord blood. Cytotherapy 7: 243-250.

94. Jaroscak J, Goltry K, Smith A, Waters-Pick B, Martin PL, et al. (2003) Augmentation of umbilical cord blood (UCB) transplantation with ex vivoexpanded UCB cells: results of a phase 1 trial using the AastromReplicell System. Blood 101: 5061-5067.

95. Astori G, Adami V, Mambrini G, Bigi L, Cilli M, et al. (2005) Evaluation of ex vivo expansion and engraftment in NOD-SCID mice of umbilical cord blood CD34+ cells using the DIDECO "Pluricell System". Bone marrow transplantation 35: 1101-1106.

96. Metheny L, Caimi P, de Lima M (2013) Cord Blood Transplantation: Can We Make it Better? Front Oncol 3: 238.

97. Sebrango A, Vicuna I, de Laiglesia A, Millan I, Bautista G, et al. (2010) Haematopoietic transplants combining a single unrelated cord blood unit and mobilized haematopoietic stem cells from an adult HLA-mismatched third party donor. Comparable results to transplants from HLA-identical related donors in adults with acute leukaemia and myelodysplastic syndromes. Best practice \& research Clinical haematology 23: 259-274.
98. Liu H, Rich ES, Godley L, Odenike O, Joseph L, et al. (2011) Reduced-intensity conditioning with combined haploidentical and cord blood transplantation results in rapid engraftment, low GVHD, and durable remissions. Blood 118 6438-6445.

99. Chen J, Wang RX, Chen F, Sun AN, Qiu HY, et al. (2014) Combination of a haploidentical SCT with an unrelated cord blood unit: a single-arm prospective study. Bone Marrow Transplant 49: 206-211.

100.Stevens CE, Carrier C, Carpenter C, Sung D, ScaradavouA (2011) HLA mismatch direction in cord blood transplantation: impact on outcome and implications for cord blood unit selection. Blood 118: 3969-3978.

101. Kanda J, Atsuta Y, Wake A, Ichinohe T, Takanashi M, et al. (2013) Impact of the direction of HLA mismatch on transplantation outcomes in single unrelated cord blood transplantation. Biology of blood and marrow transplantation: journal of the American Society for Blood and Marrow Transplantation 19 : 247-254.

102. Cunha R, Loiseau P, Ruggeri A, Sanz G, Michel G, et al. (2014) Impact of HLA mismatch direction on outcomes after umbilical cord blood transplantation fo hematological malignant disorders: a retrospective Eurocord-EBMT analysis. Bone marrow transplantation 49: 24-29.

103. Takanashi M, Atsuta Y, Fujiwara K, Kodo H, Kai S, et al. (2010) The impact of anti-HLA antibodies on unrelated cord blood transplantations. Blood 116: 2839-2846

104. Cutler C, Kim HT, Sun L, Sese D, Glotzbecker B, et al. (2011) Donorspecific anti-HLA antibodies predict outcome in double umbilical cord blood transplantation. Blood 118: 6691-6697.

105.Ruggeri L, Capanni M, Urbani E, Perruccio K, Shlomchik WD, et al. (2002) Effectiveness of donor natural killer cell alloreactivity in mismatched hematopoietic transplants. Science 295: 2097-2100.

106. Ruggeri L, Mancusi A, Burchielli E, Aversa F, Martelli MF, et al. (2006) Natural killer cell alloreactivity and haplo-identical hematopoietic transplantation. Cytotherapy 8: 554-558

107.Ruggeri L, Mancusi A, Burchielli E, Capanni M, Carotti A, et al. (2008) NK cell alloreactivity and allogeneic hematopoietic stem cell transplantation. Blood Cells Mol Dis 40: 84-90.

108. Willemze R, Rodrigues CA, Labopin M, Sanz G, Michel G, et al. (2009) KIRligand incompatibility in the graft-versus-host direction improves outcomes after umbilical cord blood transplantation for acute leukemia. Leukemia 23: 492-500.

109. Brunstein CG, Wagner JE, Weisdorf DJ, Cooley S, Noreen H, et al. (2009) Negative effect of KIR alloreactivity in recipients of umbilical cord blood transplant depends on transplantation conditioning intensity. Blood 113: 56285634

110. Garfall A, Kim HT, Sun L, Ho VT, Armand P, et al. (2013) KIR ligand incompatibility is not associated with relapse reduction after double umbilical cord blood transplantation. Bone marrow transplantation 48: 1000-1002.

111. Tanaka J, Morishima Y, Takahashi Y, Yabe T, Oba K, et al. (2013) Effects of KIR ligand incompatibility on clinical outcomes of umbilical cord blood transplantation without ATG for acute leukemia in complete remission. Blood cancer journal 3:e164

112. Castello S, Podesta M, Menditto VG, Ibatici A, Pitto A et al. (2004) Intrabone marrow injection of bone marrow and cord blood cells: an alternative way of transplantation associated with a higher seeding efficiency. Experimental hematology 32: 782-787.

113. Omae M, Inaba M, Sakaguchi Y, Tsuda M, Miyake T, et al. (2008) Long-term maintenance of donor-derived hematopoiesis by intra-bone marrow-bone marrow transplantation. Stem Cells Dev 17: 291-302.

114. Frassoni F, Gualandi F, Podestà M, Raiola AM, Ibatici A, et al. (2008) Direct intrabone transplant of unrelated cord-blood cells in acute leukaemia: a phase I/II study. Lancet Oncol 9: 831-839.

115. Okada M, Yoshihara S, Taniguchi K, Kaida K, Ikegame K, et al. (2012) Intrabone marrow transplantation of unwashed cord blood using reducedintensity conditioning treatment: a phase I study. Biology of blood and marrow transplantation: journal of the American Society for Blood and Marrow Transplantation 18: 633-639.

116. Saglio F, Berger M, Vassallo E, Nesi F, Gunetti M, et al. (2012) Intrabone cord blood hematopoietic stem cell transplantation in a subset of very high- 
Citation: Danby R, Rocha V (2014) Current Strategies to Improve Engraftment in Cord Blood Transplantation. J Stem Cell Res Ther 4: 172 doi:10.4172/2157-7633.1000172

Page 14 of 15

risk pediatric patients: a safety and feasibility pilot study. Journal of pediatric hematology/oncology 34: 359-363.

117. Rocha V, Labopin M, Ruggeri A, Podesta M, Gallamini A, et al. (2013) Unrelated cord blood transplantation: outcomes after single-unit intrabone injection compared with double-unit intravenous injection in patients with hematological malignancies. Transplantation 95: 1284-1291.

118. Avigdor A, Goichberg P, Shivtiel S, Dar A, Peled A, et al. (2004) CD44 and hyaluronic acid cooperate with SDF-1 in the trafficking of human CD34+ stem/ progenitor cells to bone marrow. Blood 103: 2981-2989.

119. Delaney C, Ratajczak MZ, Laughlin MJ (2010) Strategies to enhance umbilical cord blood stem cell engraftment in adult patients. Expert Rev Hematol 3: 273-283.

120. Christopherson KW, 2nd, Paganessi LA, Napier S, Porecha NK (2007) CD26 inhibition on CD34+ or lineage- human umbilical cord blood donor hematopoietic stem cells/hematopoietic progenitor cells improves long-term engraftment into NOD/SCID/Beta2null immunodeficient mice. Stem cells and development 16: 355-360.

121. Jimenez A, Fung HC, Christopherson KW 2nd (2011) Cellular therapies supplement: strategies for improving transplant efficiency in the context of cellular therapeutics. Transfusion 51 Suppl 4: 125S-137S.

122.Xia L, McDaniel JM, Yago T, Doeden A, McEver RP (2004) Surface fucosylation of human cord blood cells augments binding to P-selectin and E-selectin and enhances engraftment in bone marrow. Blood 104: 3091-3096.

123. Robinson SN, Simmons PJ, Thomas MW, Brouard N, Javni JA, et al. (2012) Ex vivo fucosylation improves human cord blood engraftment in NOD-SCID IL-2Rî3(null) mice. ExpHematol 40: 445-456.

124. Wadhwa PD, Lazarus HM, Koc ON, Jaroscak J, Woo D, et al. (2003) Hematopoietic recovery after unrelated umbilical cord-blood allogeneic transplantation in adults treated with in vivo stem cell factor (R-MetHuSCF) and filgrastim administration. Leukemia research 27: 215-220.

125. vanHensbergen Y, Schipper LF, Brand A, Slot MC, Welling M, et al. (2006) Ex vivo culture of human CD34+ cord blood cells with thrombopoietin (TPO) accelerates platelet engraftment in a NOD/SCID mouse model. ExpHematol 34: 943-950.

126. Yoshihara H, Arai F, Hosokawa K, Hagiwara T, Takubo K, et al. (2007) Thrombopoietin/MPL signaling regulates hematopoietic stem cell quiescence and interaction with the osteoblastic niche. Cell Stem Cell 1: 685-697.

127. Qian H, Buza-Vidas N, Hyland CD, Jensen CT, Antonchuk J, et al. (2007) Critical role of thrombopoietin in maintaining adult quiescent hematopoietic stem cells. Cell Stem Cell 1: 671-684.

128.Basser RL, O'Flaherty E, Green M, Edmonds M, Nichol J, et al. (2002) Development of pancytopenia with neutralizing antibodies to thrombopoietin after multicycle chemotherapy supported by megakaryocyte growth and development factor. Blood 99: 2599-2602.

129. Rodeghiero F, Stasi R, Giagounidis A, Viallard JF, Godeau B, et al. (2013) Long-term safety and tolerability of romiplostim in patients with primary immune thrombocytopenia: a pooled analysis of 13 clinical trials. Eur J Haematol .

130. Saleh MN, Bussel JB, Cheng G, Meyer O, Bailey CK, et al. (2013) Safety and efficacy of eltrombopag for treatment of chronic immune thrombocytopenia: results of the long-term, open-label EXTEND study. Blood 121: 537-545.

131.Sun H, Tsai Y, Nowak I, Liesveld J, Chen Y (2012) Eltrombopag, a thrombopoietin receptor agonist, enhances human umbilical cord blood hematopoietic stem/primitive progenitor cell expansion and promotes multilineage hematopoiesis. Stem cell research 9: 77-86.

132. Liesveld JL, Phillips GL, 2nd, Becker M, Constine LS, Friedberg J, et al. (2013) A phase 1 trial of eltrombopag in patients undergoing stem cell transplantation after total body irradiation. Biology of blood and marrow transplantation: journal of the American Society for Blood and Marrow Transplantation 19: 1745-1752.

133. Dominici M, Le Blanc K, Mueller I, Slaper-Cortenbach I, Marini F, et al. (2006) Minimal criteria for defining multipotentmesenchymal stromal cells. The International Society for Cellular Therapy position statement. Cytotherapy 8: 315-317.

134. Giuliani M, Oudrhiri N, Noman ZM, Vernochet A, Chouaib S, et al. (2011) Human mesenchymal stem cells derived from induced pluripotent stem cells down-regulate NK-cell cytolytic machinery. Blood 118: 3254-3262.

135. Tobin LM, Healy ME, English K, Mahon BP (2013) Human mesenchymal stem cells suppress donor CD4(+) T cell proliferation and reduce pathology in a humanized mouse model of acute graft-versus-host disease. Clinical and experimental immunology 172: 333-348.

136. Uccelli A, Moretta L, Pistoia V (2006) Immunoregulatory function of mesenchymal stem cells. Eur J Immunol 36: 2566-2573.

137. Nasef A, Chapel A, Mazurier C, Bouchet S, Lopez M, et al. (2007) Identification of IL-10 and TGF-beta transcripts involved in the inhibition of T-lymphocyte proliferation during cell contact with human mesenchymal stem cells. Gene Expr 13: 217-226.

138. Selmani Z, Naji A, Zidi I, Favier B, Gaiffe E, et al. (2008) Human leukocyte antigen-G5 secretion by human mesenchymal stem cells is required to suppress $T$ lymphocyte and natural killer function and to induce CD4+CD25highFOXP3+ regulatory T cells. Stem Cells 26: 212-222.

139. Noort WA, Kruisselbrink AB, in't Anker PS, Kruger M, van Bezooijen RL, et al (2002) Mesenchymal stem cells promote engraftment of human umbilical cord blood-derived CD34(+) cells in NOD/SCID mice. ExpHematol 30: 870-878.

140. Kim DW, Chung YJ, Kim TG, Kim YL, Oh IH (2004) Cotransplantation of thirdparty mesenchymal stromal cells can alleviate single-donor predominance and increase engraftment from double cord transplantation. Blood 103: 19411948.

141.Fei XM, Wu YJ, Chang Z, Miao KR, Tang YH, et al. (2007) Co-culture of cord blood CD34(+) cells with human BM mesenchymal stromal cells enhances short-term engraftment of cord blood cells in NOD/SCID mice. Cytotherapy 9: $338-347$

142. Bakhshi T, Zabriskie RC, Bodie S, Kidd S, Ramin S, et al. (2008) Mesenchymal stem cells from the Wharton's jelly of umbilical cord segments provide stromal support for the maintenance of cord blood hematopoietic stem cells during long-term ex vivo culture. Transfusion 48: 2638-2644.

143. Macmillan ML, Blazar BR, DeFor TE, Wagner JE (2009) Transplantation of ex-vivo culture-expanded parental haploidenticalmesenchymal stem cells to promote engraftment in pediatric recipients of unrelated donor umbilical cord blood: results of a phase I-II clinical trial. Bone marrow transplantation 43: 447-454.

144. Gonzalo-Daganzo R, Regidor C, Martín-Donaire T, Rico MA, Bautista G, et al (2009) Results of a pilot study on the use of third-party donor mesenchymal stromal cells in cord blood transplantation in adults. Cytotherapy 11: 278-288.

145. Bernardo ME, Ball LM, Cometa AM, Roelofs H, Zecca M, et al. (2011) Coinfusion of ex vivo-expanded, parental MSCs prevents life-threatening acute GVHD, but does not reduce the risk of graft failure in pediatric patients undergoing allogeneic umbilical cord blood transplantation. Bone marrow transplantation 46: 200-207.

146. Wu KH, Sheu JN, Wu HP, Tsai C, Sieber M, et al. (2013) Cotransplantation of umbilical cord-derived mesenchymal stem cells promote hematopoietic engraftment in cord blood transplantation: a pilot study. Transplantation 95: 773-777.

147. Sakaguchi S, Sakaguchi N, Asano M, Itoh M, Toda M (1995) Immunologic self-tolerance maintained by activated T cells expressing IL-2 receptor alphachains (CD25). Breakdown of a single mechanism of self-tolerance causes various autoimmune diseases. Journal of immunology 155: 1151-1164.

148. Shevach EM (2001) Certified professionals: CD4(+)CD25(+) suppressor T cells. J Exp Med 193: F41-46.

149. Stephens LA, Mottet C, Mason D, Powrie F (2001) Human CD4(+)CD25(+) thymocytes and peripheral $T$ cells have immune suppressive activity in vitro. Eur J Immunol 31: 1247-1254.

150. Fontenot JD, Gavin MA, Rudensky AY (2003) Foxp3 programs the development and function of CD4+CD25+ regulatory T cells. Nat Immunol 4 330-336.

151. Hori S, Nomura T, Sakaguchi S (2003) Control of regulatory T cell development by the transcription factor Foxp3. Science 299: 1057-1061.

152. Shevach EM, Tran DQ, Davidson TS, Andersson J (2008) The critical contribution of TGF-beta to the induction of Foxp3 expression and regulatory T cell function. Eur J Immunol 38: 915-917.

153. Hoffmann P, Ermann J, Edinger M, Fathman CG, Strober S (2002) Donortype $\mathrm{CD} 4(+) \mathrm{CD} 25(+)$ regulatory $\mathrm{T}$ cells suppress lethal acute graft-versushost disease after allogeneic bone marrow transplantation. The Journal of experimental medicine 196: 389-399. 
Citation: Danby R, Rocha V (2014) Current Strategies to Improve Engraftment in Cord Blood Transplantation. J Stem Cell Res Ther 4: 172. doi:10.4172/2157-7633.1000172

154. Edinger M, Hoffmann P, Ermann J, Drago K, Fathman CG, et al. (2003) $\mathrm{CD} 4+\mathrm{CD} 25+$ regulatory $\mathrm{T}$ cells preserve graft-versus-tumor activity while inhibiting graft-versus-host disease after bone marrow transplantation. Nature medicine 9: 1144-1150.

155. Miura Y, Thoburn CJ, Bright EC, Phelps ML, Shin T, et al. (2004) Association of Foxp3 regulatory gene expression with graft-versus-host disease. Blood 104: 2187-2193.

156.Zorn E, Kim HT, Lee SJ, Floyd BH, Litsa D, et al. (2005) Reduced frequency of FOXP3+ CD4+CD25+ regulatory $T$ cells in patients with chronic graft-versushost disease. Blood 106: 2903-2911.

157. Rezvani K, Mielke S, Ahmadzadeh M, Kilical Y, Savani BN, et al. (2006) High donor FOXP3-positive regulatory T-cell (Treg) content is associated with a low risk of GVHD following HLA-matched allogeneic SCT. Blood 108: 1291-1297.

158. Rieger K, Loddenkemper C, Maul J, Fietz T, Wolff D, et al. (2006) Mucosal FOXP3+ regulatory $T$ cells are numerically deficient in acute and chronic GvHD. Blood 107: 1717-1723.

159. Schneider M, Munder M, Karakhanova S, Ho AD, Goerner M (2006) The initial phase of graft-versus-host disease is associated with a decrease of CD4+CD25+ regulatory $T$ cells in the peripheral blood of patients after allogeneic stem cell transplantation. Clinical and laboratory haematology 28 : 382-390.

160. Magenau JM, Qin X, Tawara I, Rogers CE, Kitko C, et al. (2010) Frequency of CD4(+)CD25(hi)FOXP3(+) regulatory T cells has diagnostic and prognostic value as a biomarker for acute graft-versus-host-disease. Biology of blood and marrow transplantation: journal of the American Society for Blood and Marrow Transplantation 16: 907-914.

161. Wolf D, Wolf AM, Fong D, Rumpold H, Strasak A, et al. (2007) Regulatory T-cells in the graft and the risk of acute graft-versus-host disease after allogeneic stem cell transplantation. Transplantation 83: 1107-1113.

162. Pabst C, Schirutschke H, Ehninger G, Bornhauser M, Platzbecker U (2007) The graft content of donor T cells expressing gamma delta TCR+ and CD4+foxp3+ predicts the risk of acute graft versus host disease after transplantation of allogeneic peripheral blood stem cells from unrelated donors. Clinical cancer research: an official journal of the American Association for Cancer Research 13: 2916-2922.

163. Pastore D, Delia M, Mestice A, Carluccio P, Perrone T, et al. (2012) CD3+/ Tregs ratio in donor grafts is linked to acute graft-versus-host disease and immunologic recovery after allogeneic peripheral blood stem cell transplantation. Biology of blood and marrow transplantation: journal of the American Society for Blood and Marrow Transplantation 18: 887-893.
164. Delia M, Pastore D, Mestice A, Carluccio P, Perrone T, et al (2013) Outcome of allogeneic peripheral blood stem cell transplantation by donor graft CD3+/Tregs ratio: a single-center experience. Biology of blood and marrow transplantation: journal of the American Society for Blood and Marrow Transplantation 19: 495-499.

165. Takahata Y, Nomura A, Takada H, Ohga S, Furuno K, et al. (2004) CD25+CD4+ T cells in human cord blood: an immunoregulatory subset with naive phenotype and specific expression of forkhead box p3 (Foxp3) gene. ExpHematol 32: 622-629.

166. Mayer E, Bannert C, Gruber S, Klunker S, Spittler A, et al. (2012) Cord blood derived CD4+ CD25(high) $T$ cells become functional regulatory $T$ cells upon antigen encounter. PLoS One 7: e29355.

167. Torelli GF, Maggio R, Peragine N, Chiaretti S, De Propris MS, et al. (2012) Functional analysis and gene expression profile of umbilical cord blood regulatory T cells. Ann Hematol 91: 155-161.

168. Edinger M, Hoffmann P (2011) Regulatory T cells in stem cell transplantation: strategies and first clinical experiences. CurrOpinlmmunol 23: 679-684.

169. Di lanni M, Falzetti F, Carotti A, Terenzi A, Castellino F, et al. (2011) Tregs prevent GVHD and promote immune reconstitution in HLA-haploidentical transplantation. Blood 117: 3921-3928.

170. Nguyen VH, Zeiser R, Dasilva DL, Chang DS, Beilhack A, et al. (2007) In vivo dynamics of regulatory $T$-cell trafficking and survival predict effective strategies to control graft-versus-host disease following allogeneic transplantation. Blood 109: 2649-2656.

171. Battaglia M, Stabilini A, Roncarolo MG (2005) Rapamycin selectively expands CD4+CD25+FoxP3+ regulatory T cells. Blood 105: 4743-4748.

172. Strauss L, Whiteside TL, Knights A, Bergmann C, Knuth A, et al. (2007) Selective survival of naturally occurring human CD4+CD25+Foxp3+ regulatory T cells cultured with rapamycin. J Immunol 178: 320-329.

173. Strauss L, Czystowska M, Szajnik M, Mandapathil M, Whiteside TL (2009) Differential responses of human regulatory $T$ cells (Treg) and effector T cells to rapamycin. PLoS One 4: e5994.

174. Brunstein CG, Miller JS, Cao Q, McKenna DH, Hippen KL, et al. (2011) Infusion of ex vivo expanded $T$ regulatory cells in adults transplanted with umbilical cord blood: safety profile and detection kinetics. Blood 117: 1061 1070

175. Fujisaki J, Wu J, Carlson AL, Silberstein L, Putheti P, et al. (2011) In vivo imaging of Treg cells providing immune privilege to the haematopoietic stemcell niche. Nature 474: 216-219. 